\title{
Zinc lodide Catalyzed Synthesis of Trisubstituted Allenes from Terminal Alkynes and Ketones
}

\author{
Leandros P. Zorba, Eunate Egaña, Enrique Gómez-Bengoa, and Georgios C. Vougioukalakis* \\ Cite This: ACS Omega 2021, 6, 23329-23346 \\ Read Online
}

ABSTRACT: A straightforward, user-friendly, efficient protocol for the one pot, $\mathrm{ZnI}_{2}$-catalyzed allenylation of terminal alkynes with pyrrolidine and ketones, toward trisubstituted allenes, is described. Trisubstituted allenes can be obtained under either conventional heating or microwave irradiation conditions, which significantly reduces the reaction time. A sustainable, widely available, and lowcost metal salt catalyst is employed, and the reactions are carried out under solvent-free conditions. Among others, synthetically valuable allenes bearing functionalities such as amide, hydroxyl, or

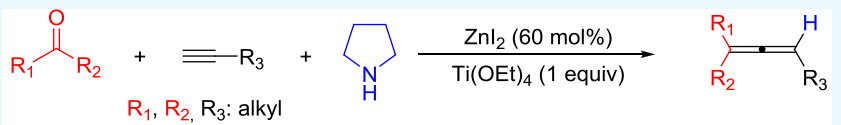

$$
\begin{aligned}
& \checkmark \text { conventional heating: } 16 \mathrm{~h} \quad \checkmark \quad 25 \text { examples (up to } 73 \% \text { ) } \\
& \checkmark \text { microwave irradiation: } 1 \mathrm{~h} \quad \checkmark \quad \text { solvent-free conditions } \\
& \checkmark \quad \text { user-friendly protocol \& readily available starting materials \& catalyst }
\end{aligned}
$$
phthalimide can be efficiently prepared. Mechanistic experiments, including kinetic isotope effect measurements and density functional theory (DFT) calculations, suggest a rate-determining [1,5]hydride transfer during the transformation of the intermediate propargylamine to the final allene.

\section{INTRODUCTION}

The chemistry of allenes has captivated the scientific community, over the past few decades, and is now regarded as one of the hot topics in Organic Chemistry. ${ }^{1}$ Once regarded as too reactive to bear any synthetic value, allenes have proven to be relatively stable moieties, also found in many natural products. ${ }^{2}$ Allenes exhibit unique chemical, conformational, and structural characteristics, as well as important applications in synthetic Organic Chemistry, catalysis, diastereoselective synthesis, and pharmaceuticals. ${ }^{1 a-c, e-g, 2,3}$ Their synthetic value is easily realized, considering the plethora of useful organic transformations they can undergo. These include cyclization and cycloaddition reactions, ${ }^{2 c, 3 k, 4}$ hydroarylations, ${ }^{5}$ hydroaminations, ${ }^{6}$ hydrocyanations, ${ }^{7}$ hydroalcoxylations, ${ }^{8}$ and hydroborations. ' In particular, when allenes bear carbonyl, amide, carboxyl, amine, or hydroxyl groups, at certain positions with regard to the allenic moiety, cyclization reactions toward heterocycles such as furans, nitrogen-containing cyclic compounds, or oxazoles take place, all having a wide range of synthetic utility. ${ }^{1 \mathrm{e}, 6 \mathrm{a}, 10}$

Due to the synthetic importance of allenes, a number of protocols have been reported in the literature. To this end, allenes can be approached by employing a variety of transformations, ${ }^{11}$ including 1,2-elimination, ${ }^{12}$ addition, ${ }^{13} \mathrm{~S}_{\mathrm{N}} 2^{\prime}$ substitution, ${ }^{14}$ Wittig-type, and related reactions, ${ }^{15}$ as well as coupling with diazo compounds. ${ }^{16}$ By carefully examining most of these synthetic approaches, one realizes that the propargylic moiety comprises a key intermediate. ${ }^{9 c, 11,16 f, 17}$ Along these lines, a strategy that has received a lot of attention lately, due to its experimental simplicity and wide substrate scope, is the synthesis of allenes from amines, carbonyl compounds, and alkynes, usually mediated by transition metal catalysts (Scheme
1). This transformation was first reported by Crabbé and coworkers in their seminal work on the synthesis of monosubstituted allenes from paraformaldehyde, diisopropylamine, and terminal alkynes (Scheme 1). ${ }^{18}$ The reaction (Crabbé homologation) is catalyzed by $\mathrm{CuBr}$. Diisopropylamine, formaldehyde, and the alkyne initially yield the corresponding propargylamine, which undergoes an intramolecular transformation to form the allene product.

Several related reports have been published ever since. The research group of Ma has significantly contributed to the field. ${ }^{19}$ Specifically, in 2002, Ma and co-workers reported a chiral approach for the synthesis of 2,3-allenoles with high ee\% (enantiomeric excess) and good to very good yields (64-79\%), under conditions analogous to those developed by Crabbé (Scheme 1). ${ }^{20}$ Later on, Nakamura and co-workers showed that the homologation of propargyl benzyl ethers to monosubstituted allenes can be performed under microwave (MW) conditions, using $\mathrm{CuBr}$ and employing dicyclohexylamine as a hydride donor. ${ }^{21} \mathrm{Ma}$ and co-workers developed two additional modified versions of the Crabbé homologation by replacing $\mathrm{CuBr}$ with $\mathrm{CuI}$, allowing the formation of monosubstituted allenes bearing amide, ether, mesylate, or hydroxyl moieties (Scheme 1). ${ }^{22}$ The use of aldehydes other than formaldehyde, for the synthesis of 1,3-disubstituted allenes, was realized only a

Received: June 12, 2021

Accepted: July 13, 2021

Published: August 31, 2021 
Scheme 1. Selected Examples for the Allenylation of Terminal Alkynes with Amines and Carbonyl Compounds monosubstituted allenes

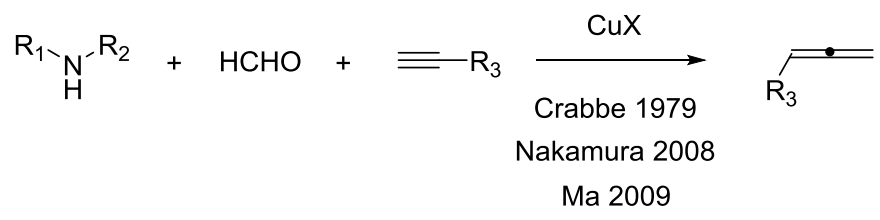

1,3-disubstituted allenes

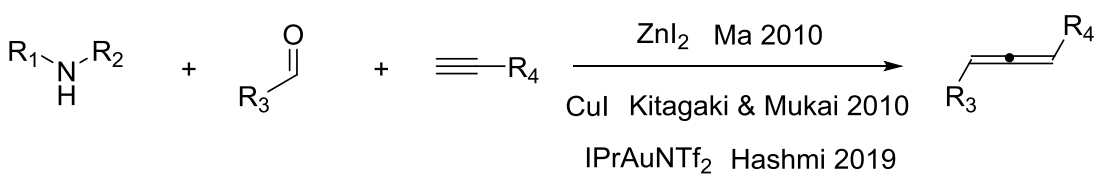

trisubstituted allenes

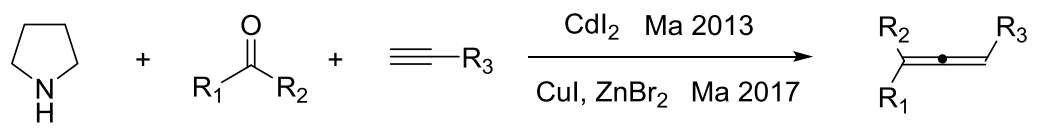

decade ago, more than 30 years after the first report on the use of paraformaldehyde. In particular, Ma and co-workers reported on the synthesis of 1,3-disubstituted allenes from alkynes, morpholine, and mainly aryl-substituted aldehydes, under $\mathrm{ZnI}_{2}$ catalysis (Scheme 1). ${ }^{23}$ Subsequently, Kitagaki, Mukai, and co-workers reported that $\mathrm{CuI}$ is also capable of performing the Crabbé homologation toward 1,3-disubstituted allenes. ${ }^{24}$ In addition to the low catalyst loading employed, the reaction was carried out under microwave irradiation; however, the reaction conditions were relatively harsh $\left(200{ }^{\circ} \mathrm{C}\right)$ and the isolated yields were moderate. Moreover, $\mathrm{Ma}$ and co-workers developed a CuIcatalyzed protocol, under conventional heating, utilizing aliphatic aldehydes, ${ }^{25}$ against which the previously reported $\mathrm{ZnI}_{2}$ protocol was not as efficient. This modified coppercatalyzed strategy also allowed the synthesis of hydroxylsubstituted allenes at the $\alpha$ - or $\beta$-position. A related, two-step approach was introduced by $\mathrm{Yu}$ and co-workers, furnishing 1,3disubstituted allenes bearing sensitivity to high-temperature functionalities. $^{26}$ Although the corresponding allenes are obtained in high yields under relatively low temperatures, the reaction conditions require stoichiometric amounts of $\mathrm{ZnI}_{2}$ (1.5 equiv), in addition to the fact that two catalysts are needed. An NHC-coordinated Au catalyst was also shown to be efficient, toward 1,3-disubstituted allenes, under low catalyst loading (2.5 mol \%) and mild conditions $\left(70{ }^{\circ} \mathrm{C}\right.$, Scheme 1). ${ }^{27}$ Minor drawbacks of this catalytic system are the prolonged reaction times $(48 \mathrm{~h})$, in addition to its focus on aryl-substituted aldehydes.

A study focusing on the capability of a variety of secondary amines to facilitate the $[1,5]$-hydride shift in propargylamines, leading to terminal or 1,3-disubstituted allenes, showed that allyl tert-butylamine (for terminal and 1,3-substituted allenes) and 1,2,3,6-tetrahydropyridine (for 1,3-disubstituted allenes) afford the best results. ${ }^{28}$ The $\alpha$-hydrogens of the amine are allylic in both cases, a fact that could rationalize the corresponding efficient hydride transfer ability.

Early reports on Au- and Ag-based catalytic protocols, developed by Che and co-workers, provide access to chiral 1,3-disubstituted allenes from preformed chiral propargylamines. $^{29}$ Chiral allenes are synthetically valuable and biologically relevant and have been found in many natural products. $^{1 b, c, 11 b, 30}$ Therefore, it comes as no surprise that the asymmetric version of the allenylation of terminal alkynes has attracted great interest. Along these lines, $\mathrm{Cu}$-catalyzed, $\mathrm{Zn}$ catalyzed, and dual catalytic systems comprising $\mathrm{Cu} / \mathrm{Zn}$ or $\mathrm{Cu} /$ $\mathrm{Cd}$ have been developed for the asymmetric synthesis of 1,3disubstituted allenes in either one- or two-step approaches. ${ }^{31}$ Chirality is achieved using a chiral amine, inducing the enantioselective formation of the in situ generated propargylamine intermediates, which are then converted to the axially chiral allenes. In some cases, a hydroxyl group residing at the $\alpha$ carbon of the alkyne moiety has been shown to positively influence the ee\% in this regard. ${ }^{31 a}$

The one-pot synthesis of trisubstituted allenes was achieved about 8 years ago, ${ }^{32} 3$ years after the allenylation of terminal alkynes to 1,3-disubstituted allenes was reported for the first time. ${ }^{23}$ Given that 1,3-disubstituted allenes are furnished by employing aldehydes, trisubstituted allenes should be in principle accessible by employing ketones as the carbonyl counterparts. Moreover, the in situ generated intermediate from the reaction of aldehydes is proposed to be a propargylamine; therefore, the analogous tetrasubstituted propargylamines should be the key intermediate species when ketones are applied. However, ketones are more challenging substrates than aldehydes, in this transformation, due to the increased steric protection of the carbonyl center and electronic effects. ${ }^{33}$ Therefore, the synthesis of propargylamines employing ketones was reported only a decade ago. ${ }^{34}$

In a seminal work, the research group of Ma reported the ability of $\mathrm{CdI}_{2}$ to catalyze the one-pot synthesis of trisubstituted allenes from alkynes, employing pyrrolidine as the amine, though with a relatively limited ketone scope (Scheme 1$).^{32}$ Notably, $\mathrm{ZnI}_{2}$ was unable to mediate this transformation above traceless amounts in the presence of toluene as a solvent, whereas although $\mathrm{CuI}$ was highly reactive for the synthesis of the precursor propargylamines, it could not conclude the transformation to the desired allenes. Very few reports have been published toward trisubstituted allenes by exploiting this kind of transformation ever since. ${ }^{19,35} \mathrm{Ma}$ and co-workers developed a two-step procedure, employing $\mathrm{CuI}$ to facilitate the first step of the reaction, toward propargylamines, followed by filtration of the crude mixture and further reaction with $\mathrm{ZnBr}_{2}$, to yield the 
Table 1. Optimization of the Reaction Conditions ${ }^{a}$

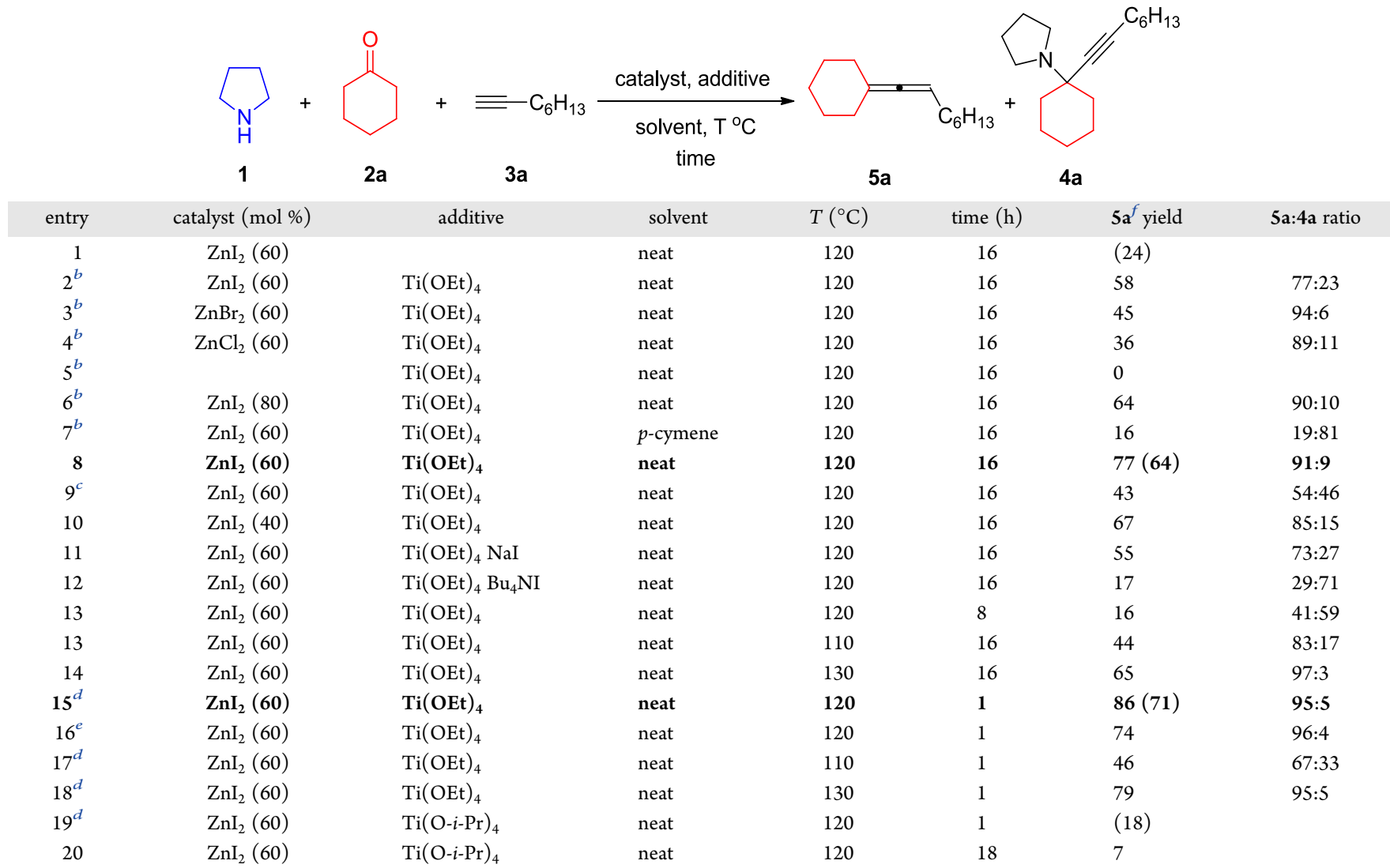

${ }^{a}$ Unless otherwise mentioned, all reagents and additives were employed in 1 equiv. ${ }^{b} 2$ equiv of $\mathrm{Ti}(\mathrm{OEt})_{4}$ were used. ${ }^{c} 0.5$ equiv of Ti(OEt $)_{4}$ were used (conventional heating). ${ }^{d}$ The reaction was performed under microwave irradiation (MW) at $300 \mathrm{~W} .{ }^{e}$ The reaction was performed under microwave irradiation (MW) at $200 \mathrm{~W} .{ }^{\text {f }}$ Yield of allene 5a in the crude mixture (isolated yields in brackets).

final allene product. ${ }^{35 a}$ A dual catalytic system, employing $\mathrm{CuI}$ and $\mathrm{ZnBr}_{2}$ in a one-pot approach, was developed by the same research group; however, 2 equiv of $\mathrm{Ti}(\mathrm{OEt})_{4}$ are also necessary for the reaction to proceed efficiently (Scheme 1). ${ }^{35 \mathrm{~b}}$

Our continuous interest in the application of sustainable metal catalysis in useful organic transformations, ${ }^{36}$ as well as the above-described importance of allenes in organic synthesis, prompted us to develop an efficient, single-catalyst protocol for the synthesis of trisubstituted allenes. In a recent work of ours, we reported the synthesis of tetrasubstituted propargylamines from amines, alkynes, and ketones under $\mathrm{Zn}(\mathrm{OAc})_{2}$ catalysis. $^{37}$ During the exploration of this transformation, using a variety of metal salts, we found that under certain conditions, $\mathrm{ZnI}_{2}$ alone can mediate the allenylation of terminal alkynes to trisubstituted allenes, though in poor yields. Given that this transformation had not been satisfactorily developed, with the reported methods using toxic metals under near stoichiometric loadings or a cocktail of catalysts, additives, and solvents, we were interested to further study the use of zinc salts. Ideally, the reaction would be catalyzed by a single, nontoxic, and inexpensive catalyst, employing stoichiometric amounts of the starting amines, alkynes, and ketones. Moreover, the protocol would preferably avoid the use of a solvent to minimize waste, also avoiding prolonged reaction times. Herein, we report our findings on such an efficient and user-friendly catalytic protocol, employing $\mathrm{ZnI}_{2}$ in the absence of the solvent, operating under either conventional heating or microwave irradiation conditions, thus substantially reducing reaction time from 16 to $1 \mathrm{~h}$ (under microwave conditions).

\section{RESULTS AND DISCUSSION}

The optimization of the reaction began using pyrrolidine ( 1 mmol), cyclohexanone ( 1 equiv), phenylacetylene ( 1 equiv), and $60 \mathrm{~mol} \% \mathrm{ZnI}_{2}$, by heating the reaction mixture for $16 \mathrm{~h}$ at $120{ }^{\circ} \mathrm{C}$. Based on the gas chromatography-mass spectrometry (GC-MS) analysis of the crude mixture, the conversion of starting materials was complete, but less than $25 \%$ yield of the corresponding trisubstituted allene was obtained (Table 1). A one-pot two-step approach was also probed, initially employing $20 \mathrm{~mol} \%$ of $\mathrm{ZnI}_{2}$ at $120^{\circ} \mathrm{C}$, followed, after $16 \mathrm{~h}$, by an addition of $60 \mathrm{~mol} \% \mathrm{ZnI}_{2}$ and heating the reaction at the same temperature for an additional $1 \mathrm{~h}$, either in the absence or in the presence of dry toluene; however, both attempts yielded poor results. When phenylacetylene was replaced with 1-octyne, slightly better results were obtained. A common strategy to activate the carbonyl moiety by rendering it more electrophilic is to use $\mathrm{Ti}(\mathrm{OEt})_{4}$ as an additive. In fact, this reagent has been used in both $\mathrm{KA}^{2}$ (ketone-amine-alkyne coupling) ${ }^{32,38}$ and allenylation reactions employing carbonyl compounds ${ }^{35 b}$ as an activating reagent. Besides increasing the electrophilicity of the carbonyl groups, $\mathrm{Ti}(\mathrm{OEt})_{4}$ also serves as a drying agent, abstracting the water produced during the course of the reaction. On this basis, when $\mathrm{Ti}(\mathrm{OEt})_{4}$ was used as an additive ( 1 equiv), after $16 \mathrm{~h}$ at $120^{\circ} \mathrm{C}$ and following chromatographic purification, 5 a was obtained in $64 \%$ isolated yield (Table 1, entry 8 ).

A number of zinc salts were then evaluated for their catalytic activity, with $\mathrm{ZnI}_{2}$ providing the best results (Table 1). Reduction or increase of $\mathrm{Ti}(\mathrm{OEt})_{4}$ equivalents to half or two, 
Scheme 2. Scope of Ketones ${ }^{a b c}$

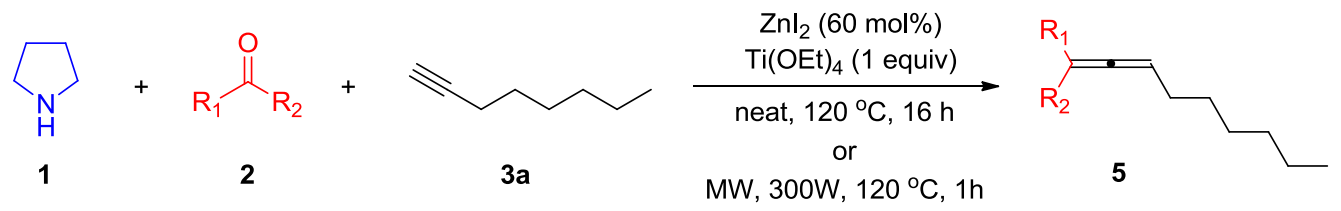

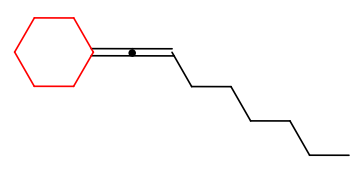

5a, ${ }^{a, b} 64 \%^{a}$ and $71 \%^{b}$

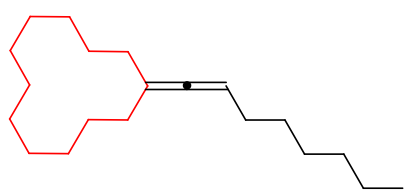

5d, ${ }^{a, b} 29 \%^{a}$ and $50 \%{ }^{b}$

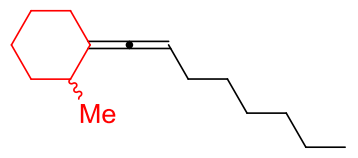

$\mathbf{5 g},{ }^{a, b} 35 \%^{a}$ and $33 \%{ }^{b}$

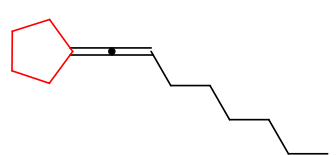

$\mathbf{5 b},{ }^{a, b} 28 \%^{a}$ and $24 \%^{b}$

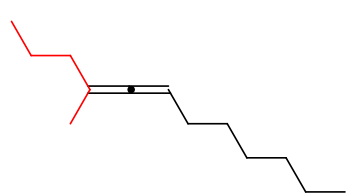

$5 e,^{a} 49 \%$

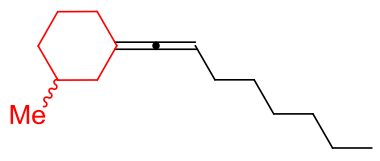

5h,,${ }^{b, c} 54 \%$

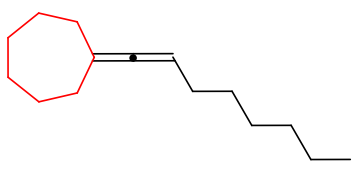

$5 c,{ }^{a} 50 \%$

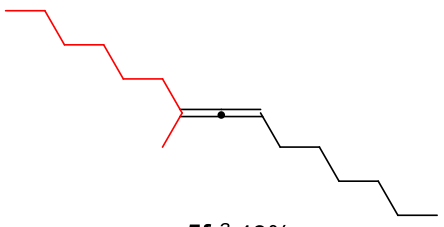

$5 f{ }^{a} 43 \%$

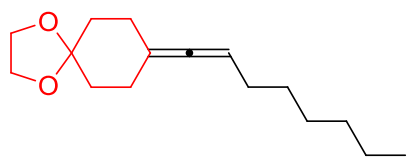

$5 \mathbf{i},{ }^{b} 37 \%$

${ }^{a}$ All reactions were carried out at a $1 \mathrm{mmol}$ scale for all reagents, $60 \mathrm{~mol} \% \mathrm{ZnI}_{2}$, and $1 \mathrm{mmol} \mathrm{Ti}(\mathrm{OEt})_{4}$. Reaction under conventional heating. ${ }^{b}$ Reaction under microwave irradiation. ${ }^{c}$ Allene $\mathbf{5 h}$ was isolated as a 2.7:1 dr diastereomeric mixture (determined by GC-MS).

respectively, led to lower $\mathbf{5 a}$ yields. Upon decreasing the catalyst loading to $40 \mathrm{~mol} \%$, the formation of 5 a decreased slightly. The presence of $\mathrm{NaI}$ or ${ }^{t} \mathrm{Bu}_{4} \mathrm{NI}$ as additional iodine sources had a negative impact on the formation of the desired allene too. We then focused on optimizing the reaction temperature and time. A decrease of the reaction time to $8 \mathrm{~h}$ lowered the allene yield, whereas the reduction or increase of the temperature to 110 or $130{ }^{\circ} \mathrm{C}$, respectively, had a negative impact on the yield of the reaction as well. In the absence of a zinc catalyst, the reaction does not take place. A series of amines were also studied for their efficiency in the formation of the desired allenes. Morpholine, piperidine, di- $n$-propylamine, $N$-allyl- $N$-tert-butylamine, 1-octylamine, cyclohexylamine, and benzylamine were tested, besides pyrrolidine. Piperidine and $\mathrm{N}$-allyl- $\mathrm{N}$-tert-butylamine afforded the best results; however, both were outperformed by pyrrolidine.

Microwave irradiation (MW) has become very attractive, over the past few decades, as an alternative means of heating up reactions, which are thus heated more efficiently, with reaction times often being substantially reduced. ${ }^{39}$ Given that alkyne allenylation under MW irradiation conditions has been reported in the past, with paraformaldehyde or substituted aldehydes as the carbonyl moieties, ${ }^{21,24}$ we tested our reaction protocol under MW conditions, resulting in the isolation of allene 5a in $71 \%$ yield after chromatographic purification. Not only was the desired product obtained in higher yield, but, equally important, the reaction time was substantially reduced to $1 \mathrm{~h}$. Prompted by the positive result, we decided to pursue further both the conventional heating and the MW irradiation protocols. Therefore, slightly more than half of the substrate scope experiments were conducted under conventional heating, and the rest of the reactions were carried out under MW irradiation, while a few reactions were set up under both protocols for comparison purposes.

Finally, upon replacing $\mathrm{Ti}(\mathrm{OEt})_{4}$ with $\mathrm{Ti}(\mathrm{O}-i-\mathrm{Pr})_{4}$, the formation of 5 a was not satisfactory under microwave irradiation conditions ( $18 \%$ isolated yield, Table 1$)$. When the same reaction was conducted under conventional heating, the isolated yield decreased even further (7\%).

With the optimized conditions in hand, we explored the scope of the reaction against a variety of ketones and alkynes. The reaction of cyclohexanone with 1-octyne gave product 5a in 64 or $71 \%$ isolated yield, under conventional heating or MW irradiation, respectively (Scheme 2). When the ring of the cyclic ketone was shortened by one methylenic group, the isolated yield decreased to 28 or $24 \%$, respectively ( $\mathbf{5 b}$, Scheme 2 ), most probably because of the increased stabilization of the ketimine cation derived from pyrrolidine and cyclopentanone, compared to that formed from pyrrolidine and cyclohexanone. Replacing cyclopentanone with cycloheptanone increased the yield of the desired allene (5c) to $50 \%$ (conventional heating), while the use of a cyclic ketone bearing an even larger ring (cyclododecanone) gave $\mathbf{5 d}$ in 29 or $50 \%$ isolated yield, under conventional heating or MW irradiation, respectively. Replacing cyclic ketones with linear aliphatic ketones resulted in a reduction of the allene yield (5e and 5f, Scheme 2). This was anticipated, given that linear ketones lack the strain release driving force related to the cyclic ketones when nucleophilically attacked by the amine.

The influence of ketone's stereochemical environment/ hindrance on the efficiency of the transformation was also 
Scheme 3. Hydroamination of 1-Octyne Observed when Bulky Ketones are Employed
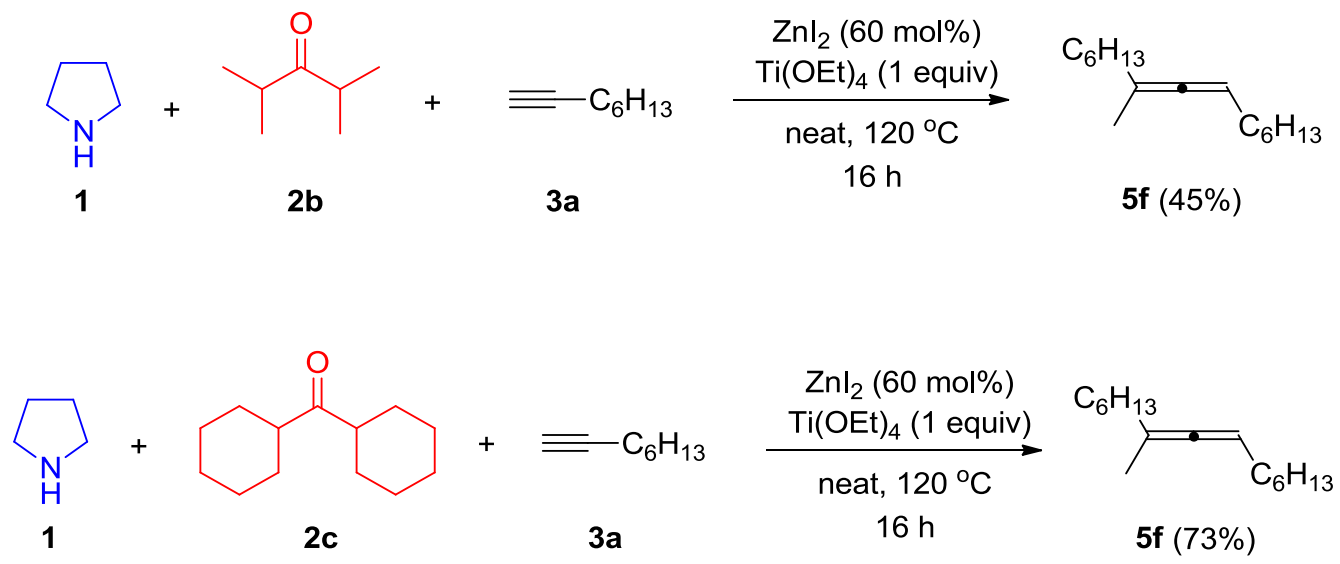

investigated by employing two ketones bearing a methyl group at the $\alpha$ - or $\beta$-position in relation to the carbonyl moiety. When 2 -methyl-cyclohexanone reacted with 1-octyne, a 35 or $33 \%$ yield of the corresponding allene $5 \mathbf{g}$ was obtained (conventional heating or MW irradiation, respectively). On the other hand, when 3-methyl-cyclohexanone reacted under MW irradiation conditions, a $54 \%$ yield of $\mathbf{5 h}$ was obtained as a diastereomeric mixture $(2.7: 1 \mathrm{dr})$. The decreased efficiency of allenylation, especially in the case of 2-methyl-cyclohexanone, can be attributed to the increased nonfavorable stereochemical interactions between the ketiminium cation and the zinc acetylide during the nucleophilic attack of the latter, leading to the propargylamine intermediate. In the case of 3-methylcyclohexanone, the methyl group is moved one carbon atom further away from the carbonyl, thus inducing a less significant stereochemical congestion to the overall outcome. When 1,4dioxaspiro[4.5] decan-8-one was subjected to the MW condition protocol, a $37 \%$ yield of allene $\mathbf{5 i}$ was obtained (Scheme 2 ). This allene compound encompasses a useful handle for additional elaboration, which can be done by removing the 1,4-dioxaspiro group and further functionalization.

3-Pentanone and 4-decanone did not allow the formation of the corresponding allenes, being essentially unreactive under our thermal condition to protocol. Interestingly, when 2,4-dimethyl3-pentanone $\mathbf{2 b}$ or dicyclohexylmethanone $\mathbf{2 c}$ were employed, the allene product obtained did not contain the ketone fragment. Instead, allene $\mathbf{5 f}$ was isolated, in $\mathbf{4 5}$ or $\mathbf{7 3} \%$ yield, respectively (Scheme 3). This observation suggests that bulkier ketones are not compatible with our protocol, instead leading to the dimerization and hydroamination of the terminal alkyne, and the subsequent formation of the corresponding allene structure, via a $[1,5]$-hydride shift, a transformation reported in the literature. $^{40}$ This transformation was not observed with the other substrates studied herein, most probably due to the fact that all other ketones used are way more reactive due to their decreased steric protection. Finally, none of the aryl ketones employed (acetophenone, $p$-MeO-, $m-\mathrm{MeO}-, p$-Cl-, and $p-\mathrm{NO}_{2}-$ acetophenone, 2-acetylpyridine, and benzophenone) afforded the desired allene, even when these were highly electrophilic, such as $p-\mathrm{NO}_{2}$-acetophenone. In the case of $p-\mathrm{MeO}-, m-\mathrm{MeO}$-, and $p$-Cl-acetophenone, no allene or propargylamine species were obtained. Instead, starting materials and unidentified byproducts were observed. In the case of $p-\mathrm{NO}_{2}$-acetophenone, only starting materials were identified, whereas in the case of 2acetylpyridine, we observed starting materials and $6 \%$ of the allene product, based on GC-MS analysis, at the end of the reaction.

The scope of the alkynes was probed next (Scheme 4). 1Octyne can efficiently react with a number of ketones, providing the corresponding allenes, as discussed above and is shown in Scheme 2. Replacing 1-octyne with 1-pentyne yielded $42 \%$ of allene $5 \mathbf{j}$ under conventional heating conditions (Scheme 4). This decrease in the isolated yield obtained for $\mathbf{5 j}$, in comparison to that for $5 \mathbf{k}$, can be attributed to the low boiling point of 1 pentyne in relation to the temperature of the reaction. The transformation is highly efficient with 4-phenyl-1-butyne, providing allene $5 \mathrm{k}$ in $73 \%$ yield for either conventional heating or MW conditions. When 3-phenyl-1-propyne was used, the yield for $\mathbf{5 1}$ decreased to $18 \%$ (conventional heating conditions). Interestingly, upon replacing the aryl group of 3-phenyl-1propyne with a cyclohexyl group, the yield for the corresponding allene $(5 \mathrm{~m})$ increased to $45 \%$. A compound bearing a phthalimide group at the a-position in relation to the alkyne moiety furnished allene $5 \mathrm{n}$ in $51 \%$ yield, whereas an amide group at the same position led to a $32 \%$ isolated yield for the desired allene 5o, as well as to a $30 \%$ yield of the intramolecular cyclization product of the alkyne, that is, the corresponding oxazole product.

Unfortunately, the presence of an ester group, instead of an amide, when $\mathbf{3 b}$ was used (Scheme 5), did not allow the formation of the desired allene. In fact, ethyl benzoate (6b) was isolated in $90 \%$ yield, originating from the nucleophilic attack of ethoxide, deriving from $\mathrm{Ti}(\mathrm{OEt})_{4}$, to the carbonyl group of $3 \mathbf{b}$, as well as $7 \%$ of allene $\mathbf{6 b}$ (Scheme 5 ). The formation of $\mathbf{6 b}$ can be rationalized by the $\mathrm{ZnI}_{2}$-catalyzed reaction between pyrrolidine, cyclohexanone, and alkyne $3 \mathbf{b}$, followed by hydrolysis of the ester group. Alternatively, or simultaneously, alkyne $\mathbf{3 b}$ can hydrolyze first, yielding the corresponding propargylic alcohol, which is then involved in the threecomponent reaction with pyrrolidine and cyclohexanone, toward $6 \mathbf{b}$.

Allenes $\mathbf{5 p}, \mathbf{5 q}$, and $\mathbf{5 r}$ were also isolated in 38,35 , and $26 \%$ yield, respectively (Scheme 4 ). These allenes show that our protocol can tolerate a number of functional groups, besides amides, phthalimides, and 1,4-dioxaspiro compounds, and can be used in late-stage functionalization strategies. Moreover, such allenes can be modified further, either on the allene moiety or the free hydroxyl group (or even at the bromide in $\mathbf{5 q}$ and $\mathbf{5 r}$ ), providing access to a variety of synthetically useful scaffolds.

The combination of the aforementioned alkynes with ketones other than cyclohexanone resulted in the synthesis of the 
Scheme 4. Scope of Alkynes ${ }^{\text {abcdefghi }}$

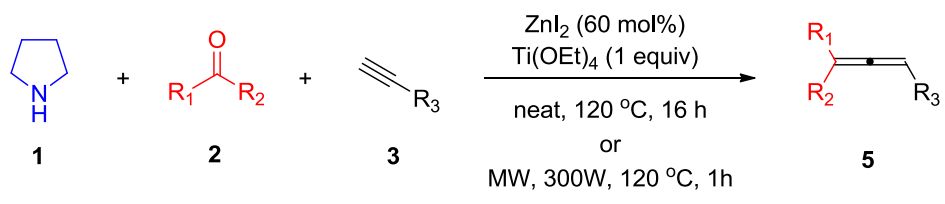

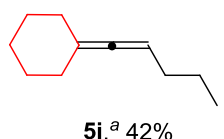

$5 \mathbf{j},{ }^{a} 42 \%$

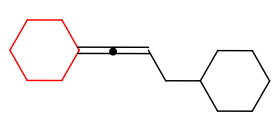

$5 \mathrm{~m}, 45 \%$

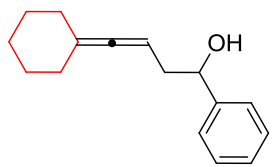

$5 p, 38 \%$
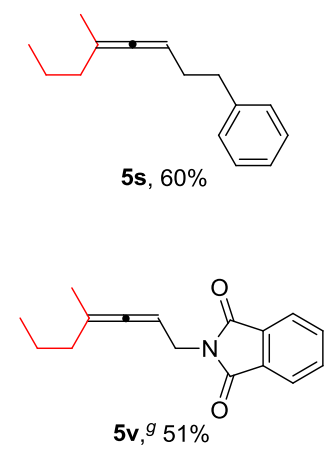

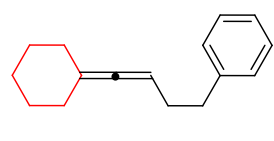

$\mathbf{5 k},{ }^{b} 73 \%$

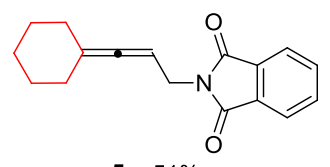

5 n, $51 \%$
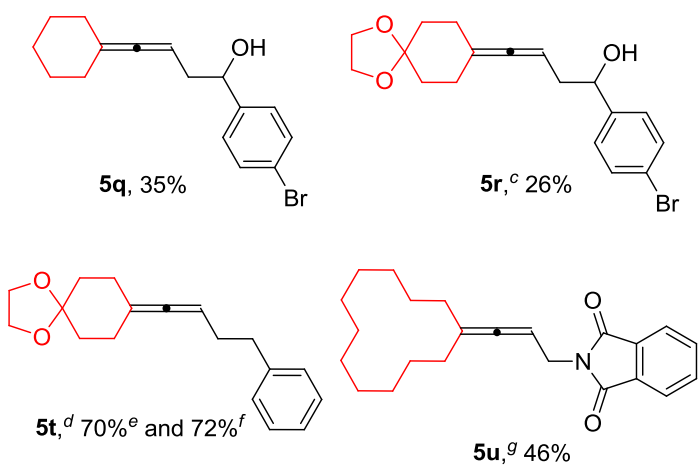

$5 u,{ }^{g} 46 \%$

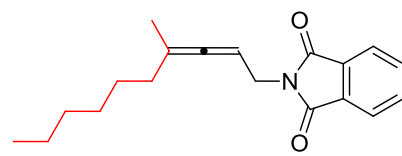

$5 w,{ }^{g} 62 \%$
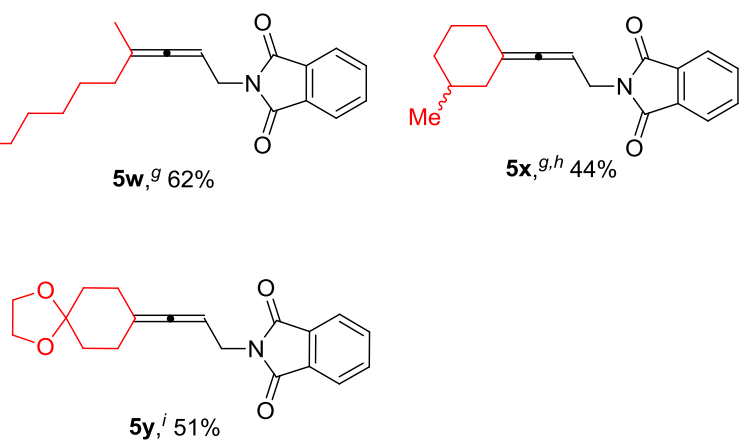

${ }^{a}$ Unless otherwise mentioned, all reagents were employed in a $1 \mathrm{mmol} \mathrm{scale}$, as well as the additive, the catalyst loading was $60 \mathrm{~mol} \%$, and the reaction was performed under conventional heating; 5 equiv of 1 -pentyne were used. ${ }^{b}$ The reaction afforded $73 \%$ of $5 \mathbf{k}$ when performed under conventional and MW conditions. ${ }^{c}$ The reaction was performed at a $0.8 \mathrm{mmol} \mathrm{scale.}{ }^{d} \mathrm{~A}$ total of $1.6 \mathrm{mmol}$ of 4-phenyl-1-butyne and pyrrolidine 1 was used. ${ }^{e}$ Allene $5 \mathbf{t}$ was isolated at $70 \%$ under conventional heating. ${ }^{f}$ Allene $\mathbf{5 t}$ was isolated at $72 \%$ under MW conditions. ${ }^{g}$ The reaction was performed under microwave conditions. ${ }^{h}$ Allene $\mathbf{5} \mathbf{x}$ was obtained as a mixture of diastereomers with 1.9:1 $\mathrm{dr}$ (determined by GC-MS). ${ }^{i} \mathrm{~A}$ total of $1.6 \mathrm{mmol}$ of pyrrolidine 1 was used.

Scheme 5. Performance of the Ester-Substituted Alkyne 3b

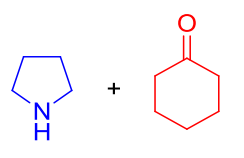

1

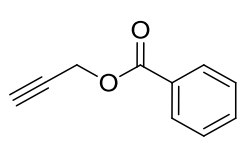

3b

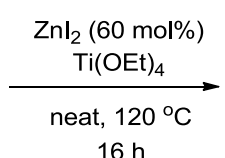

$16 \mathrm{~h}$

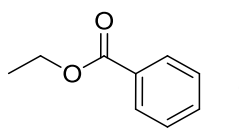

$6 a(90 \%$ yield $)$

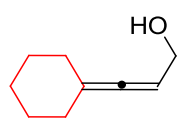

6b (7\% yield) corresponding allenes in moderate to good yields (Scheme 4). 4Phenyl-1-butyne gave the best results, allowing the isolation of allenes $5 \mathbf{s}$ and $5 \mathrm{t}$ in 60 and $70 \%$ yield, respectively, under conventional heating conditions. The isolated yield of $\mathbf{5 t}$ under 
Scheme 6. Synthesis of Dienes via the Allenylation of Terminal Alkynes
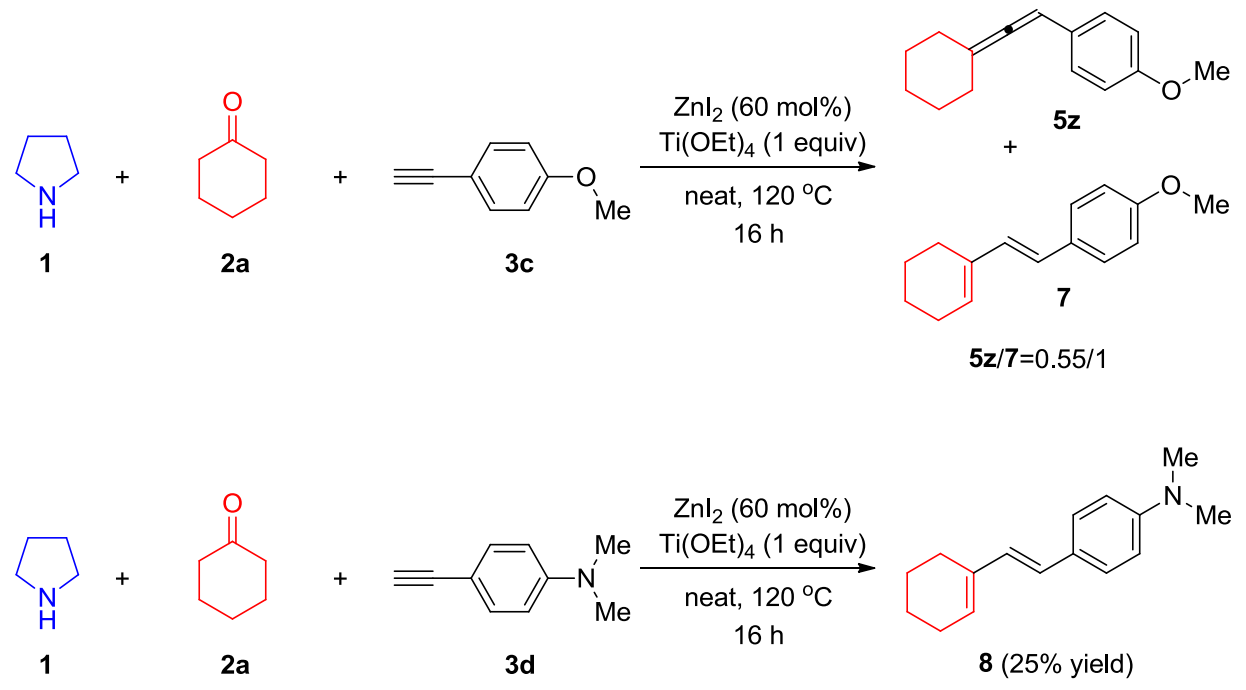

Scheme 7. Mechanistic Experiments
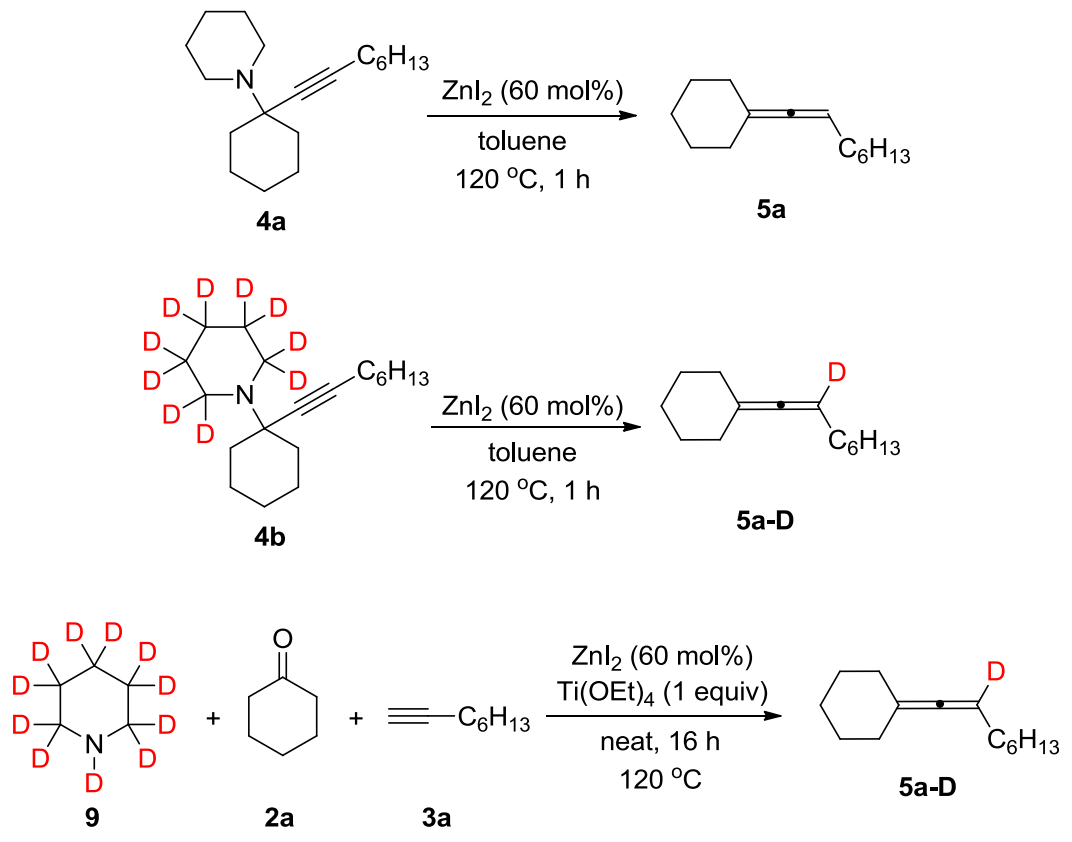

MW conditions was essentially the same as that obtained under conventional heating (72\%). Given that the phthalimide moiety provides an important handle for further functionalization, we studied the performance of $N$-propargylphthalimide with a variety of ketones other than cyclohexanone under MW irradiation conditions. Cyclic or linear ketones allowed the isolation of allenes $\mathbf{5 u}, \mathbf{5 v}, \mathbf{5 w}$, and $\mathbf{5 x}$, in $46,51,62$, and $44 \%$ yield, respectively (Scheme 4 ). Due to the fact that both the ketone and the alkyne leading to $5 y$ are solids at room temperature, this reaction was difficult to operate under MW conditions; therefore, conventional heating was used in this case, leading to a $51 \%$ isolated yield. Finally, we note that our findings described herein suggest that MW irradiation conditions, when compared to conventional heating, have either a positive or an insignificant impact on the reaction outcome, besides, of course, the greatly shortened reaction times.

In some cases of our substrate scope studies, a byproduct of dienic nature was also generated. When aliphatic alkynes were employed, the yield of this diene byproduct was very low, usually insignificant. However, when aromatic alkynes were used, diene formation became a major drawback for the isolation of the desired allene products. Phenylacetylene allowed the formation of the allenes in low yield, in addition to byproducts. Arylsubstituted alkynes bearing electron-withdrawing substituents ( $p$-Cl- and $p$ - $\mathrm{CF}_{3}$-phenylacetylene) allowed limited formation of the desired allene, with the majority of products being the enamine deriving from cyclohexanone and pyrrolidine, as well as a number of unidentified byproducts. On the other hand, when p-OMe-phenylacetylene (3c, Scheme 6) was employed, a mixture of the desired allene $\mathbf{5 z}$ and diene 7 was obtained, in a 0.55: 1 ratio, respectively. The diene product is obtained in a higher ratio when a more strongly electron-donating substituent is introduced on the aryl alkyne, as in $N, N$-dimethylaminophenylacetylene 3d (Scheme 6). In this case, diene 8 (trans diastereoisomer) was exclusively obtained in $25 \%$ isolated yield. Other phenyl acetylenes, such as $p$-Me- and $p$-Cl-substituted, 
Scheme 8. Kinetic Isotope Effect Results

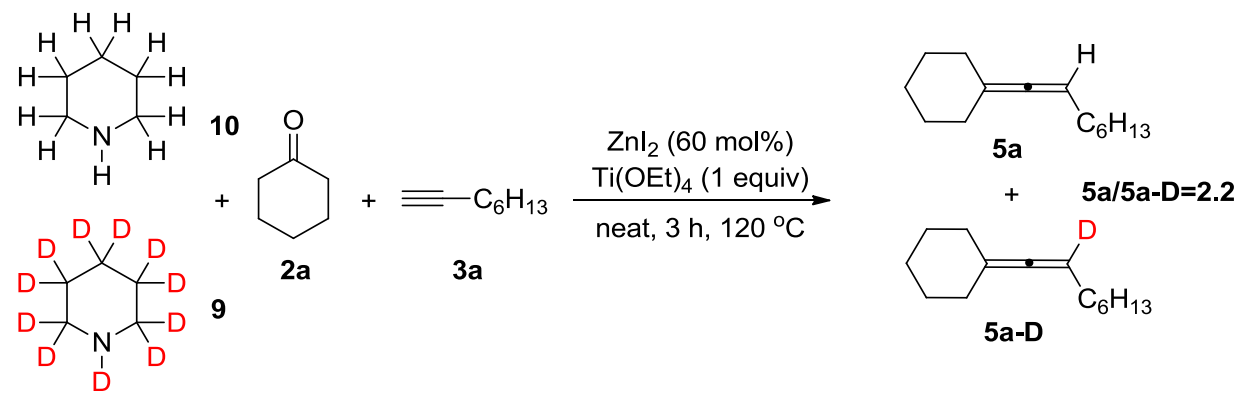

Scheme 9. Deuterium Labeling Experiment for the Diene Byproduct ${ }^{a}$
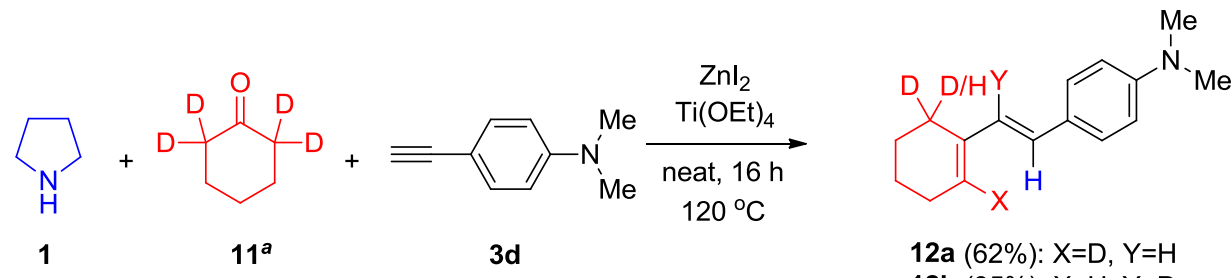

$$
\begin{aligned}
& \text { 12a }(62 \%): X=D, Y=H \\
& \text { 12b }(35 \%): X=H, Y=D \\
& \text { 12c }(3 \%): X=H, Y=H
\end{aligned}
$$

${ }^{a}$ Reaction of ketone 11 (with initial $96 \%$ deuterium atoms on the $\alpha$-carbons of the carbonyl group) toward the diene byproduct 12.

gave a mixture of inseparable additional byproducts, in addition to the mixture of the corresponding allenes and dienes.

The mechanism of terminal alkyne allenylation has been proposed to begin with the formation of a propargylamine moiety, followed by a hydride transfer that yields the allene structure. ${ }^{19-22,24-32,35}$ To identify the propargylamine species as a possible intermediate in our protocol, propargylamine 4a was heated at $120{ }^{\circ} \mathrm{C}$ for $1 \mathrm{~h}$ in the presence of $\mathrm{ZnI}_{2}$, yielding allene 5a (Scheme 7). Next, propargylamine-D10 4b was synthesized. Upon its reaction with $\mathrm{ZnI}_{2}$ for $1 \mathrm{~h}$ at $120{ }^{\circ} \mathrm{C}$, allene 5a-D was obtained, with full deuterium incorporation on the allenic carbon (Scheme 7). When piperidine-D 119 was used as the amine, under our protocol conditions, allene 5a-D was furnished, again with full deuterium incorporation at the allenic carbon (Scheme 7). These observations suggest that propargylamines are indeed the intermediate species en route to the allenes. Moreover, the allenic hydrogen originates from the amine moiety of $\mathbf{4 b}$, which is the product of an initial $\mathrm{KA}^{2}$ reaction between piperidine-D11 9, cyclohexanone, and 1octyne.

To find the rate-determining step of our protocol's transformation, a reaction was set up using a 1:1 mixture of piperidine-H11 (10) and piperidine-D11 (9), along with 1octyne and cyclohexanone, under our standard, conventional heating conditions. It is worth mentioning that the reliable measurement of the corresponding kinetic isotope effect required a very long delay time during our ${ }^{1} \mathrm{H}$ NMR studies. This is because in many of the allenes isolated, allenic protons give integrations lower than 1 (usually in the range $0.83-0.98$ ) per proton nuclei, an effect known in the literature. ${ }^{32,35}$ Although these prolonged relaxation times are not really problematic with regards to the characterization of the products, they comprise a significant problem when one wants to precisely measure a kinetic isotope effect. Fortunately, by increasing the relaxation delay $(\mathrm{d} 1)$ of the ${ }^{1} \mathrm{H}$ NMR experiment for allene 5a from the typical $1-100 \mathrm{~s}$, we found that the integration ratio was substantially improved. By increasing the relaxation delay time further, to $300 \mathrm{~s}$, the ratio of the allylic methylenic protons vs the allenic proton in 5a became 2.03:1.00. Using this relaxation delay times in our ${ }^{1} \mathrm{H}$ NMR measurements, for the intermolecular competition between piperidine-H11 and piperidine-D11, the ratio of the corresponding allenes $(\mathbf{5 a} / \mathbf{5 a}-\mathbf{D})$ was found to be 2.25 (Scheme 8 ). This measurement suggests the existence of a primary kinetic isotope effect in the overall transformation, with a value of $k_{\mathrm{H}} / k_{\mathrm{D}}=2.25 \pm 0.15$. This can be rationalized with a $\mathrm{C}-\mathrm{H} / \mathrm{C}-\mathrm{D}$ bond breaking at the ratedetermining step of the transformation. This finding is in agreement with analogous results in transformations leading to disubstituted allenes, ${ }^{18 a, 31 \mathrm{k}}$ as well as our density functional theory (DFT) calculations' results (vide infra).

To study the formation of the diene byproduct, a reaction was set up, employing pyrrolidine, 2,2,6,6-tetradeuterated-cyclohexanone (11), and N,N-dimethylamino-phenylacetylene (3d) under our standard, conventional heating reaction conditions (Scheme 9). A mixture of diene products $12 \mathbf{a}-\mathbf{c}$ was obtained. Deuterium was incorporated into two of the vinylic carbons, with the vinylic/benzylic carbon atom bearing only protons in all cases. In product $12 \mathrm{a}$, obtained in a $62 \%$ relative ratio, the deuterium atom was located at the olefinic site of the cyclohexene ring. In diene $\mathbf{1 2} \mathbf{b}$, obtained in a $35 \%$ relative ratio, the deuterium atom was located at the $\mathrm{sp}^{2}$ carbon in the $\alpha$ position with regards to the cyclohexene ring. Finally, diene 12c, in which both the above-mentioned carbon centers are connected with protons, was obtained in a $3 \%$ relative ratio (Scheme 9). The "loss" of deuterium nuclei from the vinylic carbon of the cyclohexene ring can be rationalized by the enoleketone equilibrium of deuterated ketone 11, during the course of the reaction, due to their exchange by protons deriving from the amine and the terminal alkyne. The fact that no deuterium incorporation was observed on the vinylic/benzylic carbon suggests that this proton may originate from the amine due to the $[1,5]$-hydride shift. Notably, the other carbon in 12, previously $\alpha$ to the cyclohexanone carbonyl carbon (in the product, allylic on the cyclohexane ring), was found to have a 
Scheme 10. Energy Profile for the $\mathrm{ZnI}_{2}$ Catalyzed Allenylation of 1-Octyne with Pyrrolidine and Cyclohexanone

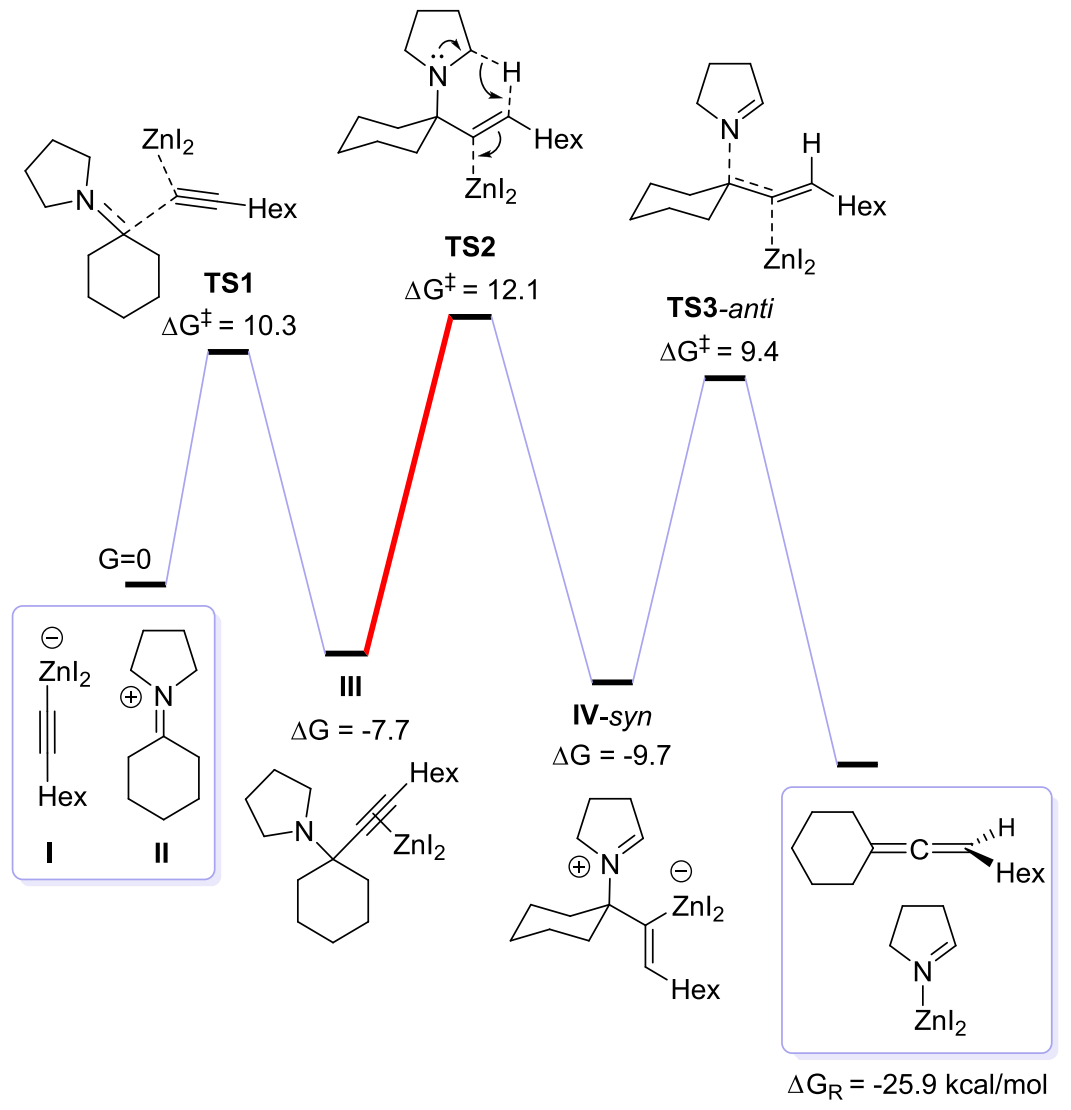

$0.76(H) / 1.24(D)$ ratio. Based on these findings and related literature precedence, ${ }^{41}$ we hypothesize that the allene product is a precursor to the diene byproduct, which is most probably obtained via the activation of the allene moiety by $\mathrm{ZnI}_{2}$.

To gain further insight into the overall terminal alkyne allenylation reaction mechanism, we carried out DFT calculations with the Gaussian 16 suite of programs, using B3LYP functional, together with the 6-31G(d,p) basis set for the structure optimizations and M06-2X/def2tzvpp for the singlepoint energy refinements. To mimic the reaction conditions, we used an implicit solvent model (IEFPCM) with toluene as the solvent. As reagent models for the calculations, pyrrolidine (1), cyclohexanone (2a), 1-octyne (3a), and $\mathrm{ZnI}_{2}$ were used. As previously computed in a related system, ${ }^{36 f}$ the initial deprotonation of 1-octyne generates alkynyl-Zn complex I, and its attack to iminium electrophile II presents an activation energy of only $10.3 \mathrm{kcal} / \mathrm{mol}$ (TS1, Scheme 10), forming neutral species III in an exothermic process. Next, the critical step of $\mathrm{H}$ transfer was calculated, finding the transition step TS2, with an energy of $12.1 \mathrm{kcal} / \mathrm{mol}$, relative to the starting materials I + II, which corresponds to an activation of $19.8 \mathrm{kcal} / \mathrm{mol}$ from III.

According to the activation energies in Scheme 10, the $\mathrm{H}$ transfer is rate limiting (TS2, $\Delta G^{\ddagger}=19.8 \mathrm{kcal} / \mathrm{mol}$ ), but the elimination step could in principle compete $\left(\Delta G^{\ddagger}=19.1 \mathrm{kcal} /\right.$ $\mathrm{mol}$ ) in certain circumstances (vide infra). Also, the energy of TS2 seems too low for the experimental reaction temperature $\left(120^{\circ} \mathrm{C}\right)$, and thus, the agreement between the experiments and calculations was not complete at this point. The zwitterionic $\mathrm{Zn}$ alkenyl species IV presents two main conformers depending on the relative anti or syn disposition of the imminium and zinc moieties. Not surprisingly, the energetically lowest conforma- tion of IV is syn (as shown in Scheme 10), placing the negative and positive charges close to each other, whilst the elimination through TS3 prefers an anti-orientation. Indeed, the activation energies for the anti $(9.4 \mathrm{kcal} / \mathrm{mol}$, TS3-anti) and syn $(12.1 \mathrm{kcal} /$ $\mathrm{mol}$ ) elimination pathways differ substantially, allowing to safely discard the syn option. In this regard, it is interesting to note that both the triple bond and the amine can coordinate the $\mathrm{ZnI}_{2}$ salt in complex III, but, as shown in Scheme 11, the $\mathrm{N}-\mathrm{Zn}$ coordination in III- $\mathrm{N}$ is stronger by about $5 \mathrm{kcal} / \mathrm{mol}$ than the alkyne coordination in III-yne. This observation is crucial since III- $N$ can be considered the steady state of the reaction,

Scheme 11. Zn-yne vs Zn-N Coordination Modes during the 1,5-Hydride Transfer

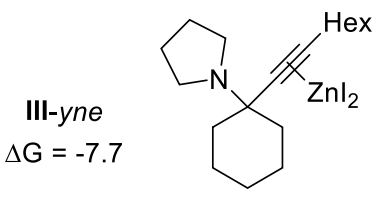<smiles>C=[Tl]</smiles><smiles>[R]C#CC1(N2CCCC2)CCCCC1</smiles>

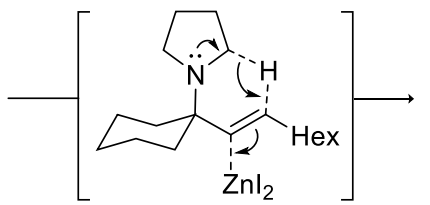

TS2

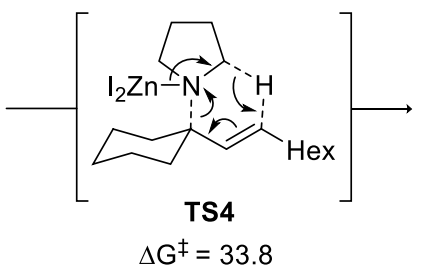


Scheme 12. Proposed Mechanism

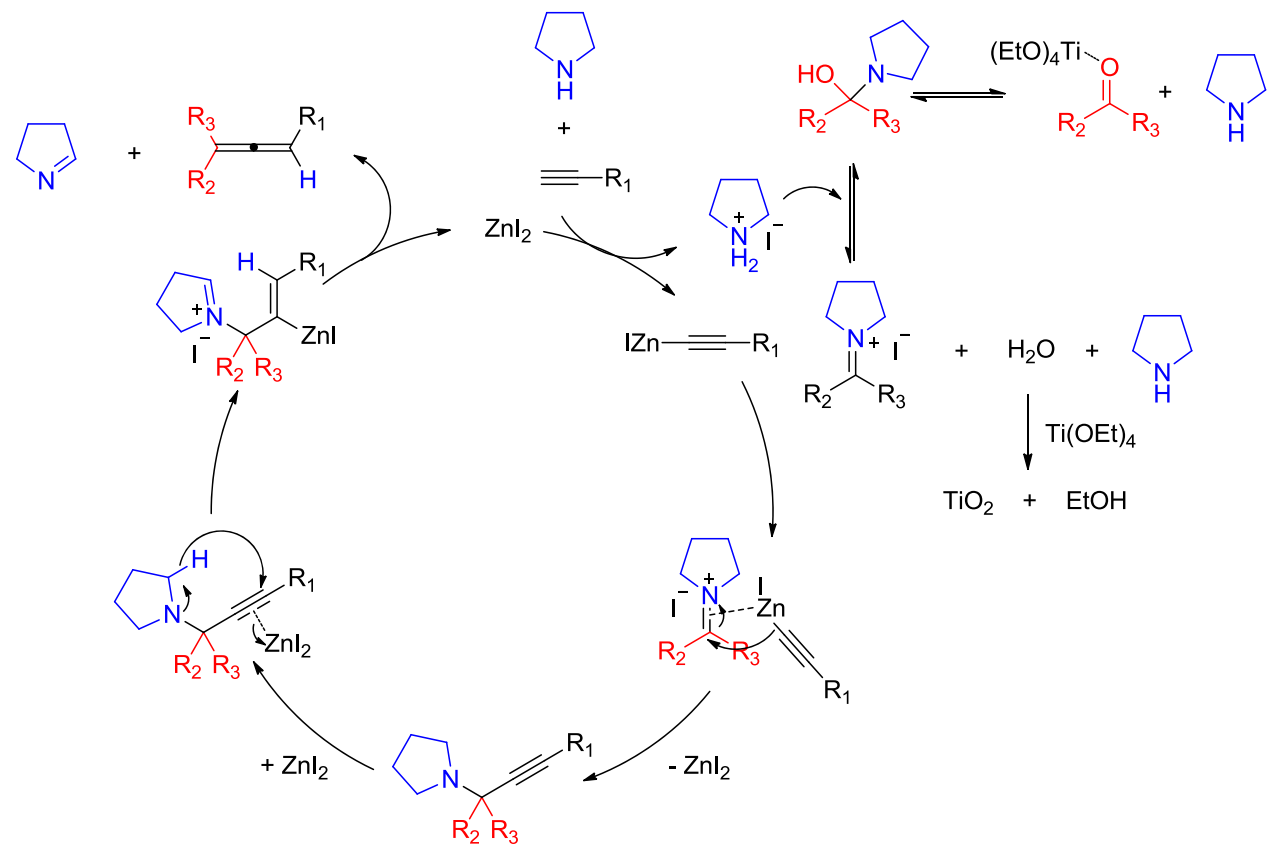

increasing the computed activation energy of the rate-limiting TS2 to $25.5 \mathrm{kcal} / \mathrm{mol}$, which perfectly explains the KIE and the reaction temperature. This scenario also led us to consider an alternative $\mathrm{H}$-transfer mechanism from III- $\mathrm{N}$, where the $\mathrm{H}$-shift and $\mathrm{ZnI}_{2}$-elimination would occur in a concerted manner through a cyclic transition state (TS4), with concomitant cleavage of the $\mathrm{C}-\mathrm{N}$ bond and $\mathrm{H}$ transfer from the pyrrolidine ring to the alkyne fragment. However, TS4 presents a very large activation energy $\left(\Delta G^{\ddagger}>45 \mathrm{kcal} / \mathrm{mol}\right)$, being unable to compete with the relatively lower energies of the two-step process in TS2 and TS3-anti.

Based on the above-described mechanistic studies and theoretical calculations, as well as literature precedence on related transformations, ${ }^{32,35}$ we propose a possible mechanism shown in Scheme 12. Initially, the amine reacts with the ketone providing a ketiminium cation, a process assisted by the preformed ammonium cation (proton donor) and enhanced by the presence of the Lewis acid $\mathrm{Ti}(\mathrm{OEt})_{4}$, which interacts with the carbonyl group, effectively increasing its electrophilicity. The alkyne reagent reacts with the $\mathrm{ZnI}_{2}$ catalyst, forming the zinc acetylide, a process most probably supported by the amine. This in situ generated zinc acetylide nucleophilically attacks the ketiminium cation, forming the propargylamine intermediate, in addition to one molecule of water, which reacts with $\mathrm{Ti}(\mathrm{OEt})_{4}$, to give ethanol. Activation of the triple bond of the propargylamine intermediate by $\mathrm{ZnI}_{2}$ enables a [1,5]-hydride transfer, which is the rate-determining step of the reaction, leading to the removal of the amine component, as well as the zinc catalyst, furnishing the final allene.

\section{CONCLUSIONS}

Herein, we are presenting a straightforward synthetic protocol for the allenylation of terminal alkynes with ketones and pyrrolidine, toward trisubstituted allenes, under inexpensive, sustainable, and widely available $\mathrm{ZnI}_{2}$ catalysis. The one-pot reaction requires stoichiometric amounts for all three reactants, as well as more sustainable conditions and reduced catalyst loading, compared to all analogous protocols reported thus far in the literature. $\mathrm{Ti}(\mathrm{OEt})_{4}$ is also used to activate the carbonyl group and scavenge water. Our protocol does not require the use of solvent and is efficient either under conventional heating or MW irradiation conditions, which substantially reduce reaction time. A variety of alkynes and aliphatic ketones have been successfully employed. Equally important, the protocol is functional-group tolerant and, therefore, can be employed in late-stage functionalization steps. Mechanistic investigations revealed that the allenic proton originates from the amine utilized. Moreover, the key intermediate to the allenes is the corresponding propargylamine compound. Kinetic isotope effect measurements and DFT calculations suggest that the 1,5-hydride transfer, transforming the intermediate propargylamines to the corresponding allenes, is the rate-limiting step of the overall transformation. We also present a brief study on the related formation of 1,3-dienes, which are the byproducts for some specific substrates utilized. These findings may prove helpful toward designing a new method for the synthesis of 1,3dienes.

\section{EXPERIMENTAL SECTION}

4.1. General Information. All chemicals, starting materials, and catalysts were received from commercial sources, and the majority of these were used without further purification, with the exception of cyclohexanone and pyrrolidine, which were distilled prior to their use. All reactions were carried out under an argon atmosphere in flame-dried, Teflon-sealed screw-cap pressure tubes or Schlenk tubes. The course of the reactions was monitored via GC-MS or thin layer chromatography (TLC), using silica gel 60 coated aluminum sheets $(0.2 \mathrm{~mm})$, absorbing at $254 \mathrm{~nm}$ (silica gel $60 \mathrm{~F} 254$ ), as well as using a potassium permanganate solution for visualization. All products were isolated by high-pressure gradient column chromatography, using silica gel 60 (230-400 mesh) and mixtures of hexanes/ ethyl acetate as the eluent.

NMR spectra were recorded on Bruker Avance- $400 \mathrm{MHz}$ or Varian Mercury $200 \mathrm{MHz}$ instruments, using $\mathrm{CDCl}_{3}$ as a solvent and its residual solvent peak as a reference. NMR spectroscopic 
data are given in the order: chemical shift, multiplicity (s, singlet, br, broad, d, doublet, t, triplet, q, quartet, dd, doublet of doublets, $\mathrm{dt}$, doublet of triplets, $\mathrm{m}$, multiplet), coupling constant in hertz $(\mathrm{Hz})$, and a number of protons. High-resolution mass spectrometry (HRMS) spectra were recorded using a QTOF maxis Impact (Bruker) spectrometer with electron spray ionization (ESI). GC-MS spectra were recorded with a Shimadzu GCMS-QP2010 Plus Chromatograph Mass Spectrometer using a MEGA (MEGA-5, FT: $0.25 \mu \mathrm{m}$, ID: $0.25 \mathrm{~mm}$, L: $30 \mathrm{~m}, T_{\max }: 350{ }^{\circ} \mathrm{C}$, Column ID no. 11475$)$ column, using chloroform as a solvent.

4.2. General Procedure for the Synthesis of Alkynes. 4.2.1. N-(Prop-2-yn-1-yl)benzamide (Used for Allene 5o). To a two-necked flask, flame-dried and purged with Ar, benzoic acid $(1.221 \mathrm{~g}, 10 \mathrm{mmol}, 1$ equiv), 1 -ethyl-3-(3dimethylaminopropyl)carbodiimide (EDC) hydrochloride (2.75 g, $15 \mathrm{mmol}, 1.5$ equiv), HOBt (2.027 g, $15 \mathrm{mmol}, 1.5$ equiv), and $15 \mathrm{~mL}$ of dry dichloromethane (DCM) were added. The reaction mixture was stirred for $10 \mathrm{~min}$ and then cooled to 0 ${ }^{\circ} \mathrm{C}$. Afterward, 2-propynylamine dissolved in $5 \mathrm{~mL}$ of dry DCM was added, and the reaction was allowed to return to room temperature and react under these conditions for $18 \mathrm{~h}$. The reaction mixture was washed with a $5 \%$ aqueous citric acid solution (twice) and, afterward, with a $10 \%$ aqueous $\mathrm{K}_{2} \mathrm{CO}_{3}$ (twice). The organic layer was then dried over $\mathrm{MgSO}_{4}$, filtered, and the solvent was removed in vacuo to furnish a white solid, which was purified by gradient column chromatography, allowing the isolation of $N$-(Prop-2-yn-1-yl)benzamide as a white solid. Spectral analysis for $N$-(Prop-2-yn-1-yl)benzamide agrees with the reported spectral data found in the literature. ${ }^{42}$

4.2.2. Prop-2-yn-1-yl Benzoate (3b). To a two-necked flask, flame-dried and purged with Ar, containing benzoic acid (1 g, $8.2 \mathrm{mmol}, 1$ equiv) and $10 \mathrm{~mL}$ of dry dimethylformamide (DMF), potassium carbonate $(2.263 \mathrm{~g}, 16.4 \mathrm{mmol}, 2$ equiv) and propargyl bromide ( $1.461 \mathrm{~g}, 12.3 \mathrm{mmol}, 1.5$ equiv) dissolved in $5 \mathrm{~mL}$ of dry DMF were added at $0{ }^{\circ} \mathrm{C}$. The reaction was allowed to return to room temperature and was left to react at these conditions for $18 \mathrm{~h}$. The mixture was quenched using a saturated aqueous solution of $\mathrm{NH}_{4} \mathrm{CO}_{3}$, followed by extraction (three times) with ethyl acetate. The organic phase was washed with water and a saturated $\mathrm{NaCl}$ aqueous solution, dried over $\mathrm{MgSO}_{4}$ and, after removal of the solvents in vacuo, alkyne $\mathbf{3 b}$ was isolated as an orange oil. Spectral analysis for $\mathbf{3 b}$ is in accordance with the reported spectra in the literature. ${ }^{43}$

4.2.3. 1-Phenylbut-3-yn-1-ol (Used for Allene 5p). To a twonecked flask, flame-dried and purged with Ar, connected with a reflux condenser and a dropping funnel, and containing granulated magnesium ( $486 \mathrm{mg}, 20 \mathrm{mmol}, 4$ equiv), mercury hydrochloride ( $13.6 \mathrm{mg}, 0.05 \mathrm{mmol}, 0.01$ equiv) in $5 \mathrm{~mL}$ dry diethyl ether and a solution of propargyl bromide $(595 \mathrm{mg}, 5$ mmol, 1 equiv) in $5 \mathrm{~mL}$ dry diethyl ether were added dropwise. After the mixture turned gray, the second mixture of benzaldehyde ( $530 \mathrm{mg}, 5 \mathrm{mmol}, 1$ equiv) in $10 \mathrm{~mL}$ of dry diethyl ether was added dropwise at $0{ }^{\circ} \mathrm{C}$. The reaction mixture was allowed to return to room temperature and was left under stirring at these conditions for $18 \mathrm{~h}$. The mixture was neutralized by the addition of an aqueous solution of hydrochloric acid (1 $\mathrm{M})$, followed by filtration through a Buchner funnel through a short silica gel pad. Upon removing the solvent in vacuo, the resulting residue was purified by gradient column chromatography using a mixture of hexanes/ethyl acetate to yield $83 \%$ of alkyne 1-Phenylbut-3-yn-1-ol. Spectral analysis for 1-Phenylbut- 3-yn-1-ol is in agreement with the reported spectra in the literature. $^{44}$

4.2.4. 1-(4-Bromophenyl)but-3-yn-1-ol (Used for Allenes $5 q$ and $5 r$ ). To a two-necked flask, flame-dried and purged with $\mathrm{Ar}$, connected with a reflux condenser and a dropping funnel, and containing granulated magnesium $(486 \mathrm{mg}, 20 \mathrm{mmol}, 4$ equiv), mercury hydrochloride (13.6 mg, $0.05 \mathrm{mmol}, 0.01$ equiv) in $5 \mathrm{~mL}$ dry diethyl ether and a solution of propargyl bromide ( $595 \mathrm{mg}, 5 \mathrm{mmol}, 1$ equiv) in $5 \mathrm{~mL}$ diethyl ether were added dropwise. After the mixture turned gray, a mixture of 4bromo-benzaldehyde ( $995 \mathrm{mg}, 5 \mathrm{mmol}, 1$ equiv) in $10 \mathrm{~mL}$ of dry diethyl ether was added dropwise at $0{ }^{\circ} \mathrm{C}$. The reaction mixture was allowed to return to room temperature and was left at these conditions for $18 \mathrm{~h}$. The mixture was neutralized by the addition of an aqueous solution of hydrochloric acid (1 M), followed by filtration through a Buchner funnel through a short silica gel pad. The resulting residue, after removing the solvents in vacuo, was identified as 1-(4-bromophenyl)but-3-yn-1-ol and required no further purification. Spectral analysis for 1-(4-bromophenyl)but-3-yn-1-ol is in agreement with the reported spectra in the literature. $^{44}$

4.3. General Procedure for the Synthesis of 2.2.6.6Tetradeuterated-cyclohexanone (11). To a round bottom flask, flame-dried and purged with Ar, equipped with a reflux condenser, cyclohexanone ( $393 \mathrm{mg}, 4 \mathrm{mmol}, 1$ equiv), $\mathrm{K}_{2} \mathrm{CO}_{3}$ ( $44 \mathrm{mg}, 0.32 \mathrm{mmol}, 0.08$ equiv), and $6 \mathrm{~mL} \mathrm{D}_{2} \mathrm{O}$ were added. The reaction mixture is heated at reflux conditions for $108 \mathrm{~h}$. The resulting solution was extracted with diethyl ether (three times) and dried over $\mathrm{MgSO}_{4}$, filtered, and the solvent was removed under reduced pressure, leading to the isolation of ketone 11 in $61 \%$ yield, with $96 \%$ deuterium incorporation at the $\alpha$-carbons of the carbonyl group. ${ }^{45}$

4.4. General Procedure for the Synthesis of Propargylamine 4a. To a Teflon-sealed screw-cap pressure tube, flamedried and purged with $\mathrm{Ar}, \mathrm{CuI}(76 \mathrm{mg}, 0.4 \mathrm{mmol}, 0.2$ equiv), cyclohexanone (196 mg, 2 mmol, 1 equiv), 1-octyne ( $220 \mathrm{mg}, 2$ mmol, 1 equiv), and piperidine-H1 1 ( $170 \mathrm{mg}, 2 \mathrm{mmol}, 1$ equiv) were added. The reaction vessel was sealed with a screw cap and was heated at $120^{\circ} \mathrm{C}$ for $18 \mathrm{~h}$. The reaction mixture was filtered through a silica-coated pad and was purified via gradient column chromatography, using a mixture of hexanes/ethyl acetate as an eluent, yielding $31 \%$ of $\mathbf{4 a}$ as an orange oil. ${ }^{46}$

4.5. General Procedure for the Synthesis of Propargylamine 4b. To a Schlenk tube, flame-dried and purged with Ar, $\mathrm{CuCl}_{2}$ (6.7 mg, $0.05 \mathrm{mmol}, 0.1$ equiv), cyclohexanone (50 mg, $0.5 \mathrm{mmol}, 1$ equiv), 1 -octyne ( $55 \mathrm{mg}, 0.5 \mathrm{mmol}, 1$ equiv), and piperidine-D 11 ( $48 \mathrm{mg}, 0.5 \mathrm{mmol}, 1$ equiv) were added. The reaction tube was sealed with a screw cap and was heated at 110 ${ }^{\circ} \mathrm{C}$ for $20 \mathrm{~h}$. The reaction mixture was filtered through a Buchner funnel having a short silica gel pad, and, following the removal of the solvent in vacuo, was purified via gradient column chromatography, using a mixture of hexanes/ethyl acetate as an eluent, yielding $42 \%$ of $\mathbf{4 b}$ as an orange oil. ${ }^{47}$

4.6. General Procedure for the Kinetic Isotope Effect Studies. To a Teflon-sealed screw-cap pressure tube, flamedried and argon purged, containing a magnetic stirring bar, 60 mol \% of $\mathrm{ZnI}_{2}$ (0.6 mmol, 0.6 equiv), $\mathrm{Ti}(\mathrm{OEt})_{4}(1 \mathrm{mmol}, 1$ equiv), 1-octyne ( $1 \mathrm{mmol}, 1$ equiv), cyclohexanone ( $1 \mathrm{mmol}, 1$ equiv), and an equimolar mixture of piperidine-H11 and piperidine-D11 (0.5 mmol piperidine-H11 and $0.5 \mathrm{mmol}$ piperidine-D11) were added, respectively. The reaction tube was then sealed and left to react for $3 \mathrm{~h}$ at $120^{\circ} \mathrm{C}$ in a preheated oil bath. Afterward, the reaction mixture was cooled, diluted with 
$\mathrm{CHCl}_{3}$, and filtered through a short silica gel pad, followed by the removal of the solvent in vacuo, leading to the crude reaction mixture. This was dry loaded on $\mathrm{SiO}_{2}$ column and was purified via flash column chromatography, using hexane as the eluent. This procedure was repeated three times, yielding allenes $5 \mathbf{a}$ and 5a-D with a relative ratio of $2.25: 1$.

4.7. General Procedures for the Synthesis of Allenes 5. All reactions were set up according to one of the following two experimental procedures:

Procedure A: To a Teflon-sealed screw-cap pressure tube or a Schlenk tube, flame-dried and purged with Ar, containing a magnetic stirring bar, $60 \mathrm{~mol} \%$ of $\mathrm{ZnI}_{2}$ ( $0.6 \mathrm{mmol}, 0.6$ equiv) was added, followed by the addition of $\mathrm{Ti}(\mathrm{OEt})_{4}(1 \mathrm{mmol}, 1$ equiv). Afterward, the alkyne ( $1 \mathrm{mmol}, 1$ equiv), ketone (1 mmol, 1 equiv), and pyrrolidine ( $1 \mathrm{mmol}, 1$ equiv) were added sequentially. The reaction tube was then sealed and left to react for $16 \mathrm{~h}$ at $120{ }^{\circ} \mathrm{C}$ in a preheated oil bath. The reaction mixture was then cooled to room temperature. The addition of chloroform or ethyl acetate and filtration through a short silica gel pad, followed by the removal of the solvent in vacuo, led to the crude reaction mixture, which was purified via gradient column chromatography, using a mixture of hexanes/ethyl acetate as the eluent. When the crude mixture was not solid, dry loading on the column chromatography is more efficient. All products were characterized by ${ }^{1} \mathrm{H}$ NMR and ${ }^{13} \mathrm{C} \mathrm{NMR}$, and, for the compounds not reported in the literature HRMS as well. All spectra obtained were in agreement with the assigned structures.

Procedure B: To a microwave pressure tube, flame-dried and purged with Ar, containing a magnetic stirring bar, $60 \mathrm{~mol} \%$ of $\mathrm{ZnI}_{2}$ ( $0.6 \mathrm{mmol}, 0.6$ equiv) was added, followed by the addition of $\mathrm{Ti}(\mathrm{OEt})_{4}(1 \mathrm{mmol}, 1$ equiv $)$. Afterward, the alkyne $(1 \mathrm{mmol}$, 1 equiv), ketone ( $1 \mathrm{mmol}, 1$ equiv), and pyrrolidine ( $1 \mathrm{mmol}, 1$ $\mathrm{mmol}$ ) were added sequentially. The reaction tube was then sealed and irradiated for $1 \mathrm{~h}$, at $120^{\circ} \mathrm{C}$, at $300 \mathrm{~W}$. The reaction mixture was then cooled to room temperature. The addition of chloroform or ethyl acetate and filtration through a short silica gel pad followed, and, after the removal of the solvent in vacuo, the crude mixture was purified via gradient column chromatography, where a mixture of hexanes/ethyl acetate was used as the eluent. When the crude mixture was not solid, the dry loading of the crude mixture was more efficient. All products were characterized by ${ }^{1} \mathrm{H}$ NMR and ${ }^{13} \mathrm{C} N M R$, and for the compounds not reported in the literature HRMS as well. All spectra obtained were in agreement with the assigned structures.

4.7.1. Oct-1-en-1-ylidenecyclohexane $(5 a){ }^{35 b}$ Allene 5a was synthesized via procedures $\mathrm{A}$ and $\mathrm{B}$ and was obtained as a colorless oil in $64 \%(123 \mathrm{mg})$ and $71 \%(136 \mathrm{mg})$ yield, respectively. ${ }^{1} \mathrm{H}$ NMR $\left(400 \mathrm{MHz}, \mathrm{CDCl}_{3}\right): \delta 5.00-4.90(\mathrm{~m}$, $1 \mathrm{H}), 2.18-2.03(\mathrm{~m}, 4 \mathrm{H}), 1.95(\mathrm{q}, J=7.0 \mathrm{~Hz}, 2 \mathrm{H}), 1.67-1.46$ (m, 6H), $1.44-1.21(\mathrm{~m}, 8 \mathrm{H}), 0.93-0.84(\mathrm{t}, J=6.5 \mathrm{~Hz}, 3 \mathrm{H})$; ${ }^{13} \mathrm{C}\left\{{ }^{1} \mathrm{H}\right\} \mathrm{NMR}\left(101 \mathrm{MHz}, \mathrm{CDCl}_{3}\right): \delta 198.5,102.4,88.9,32.0$, $31.9,29.5,29.3,28.8,27.7,26.4,22.9,14.3$.

4.7.2. Oct-1-en-1-ylidenecyclopentane (5b). Allene $\mathbf{5 b}$ was synthesized via procedures $\mathrm{A}$ and $\mathrm{B}$ and was obtained as a colorless oil in $28 \%(50 \mathrm{mg}$ ) and $24 \%$ (43 $\mathrm{mg}$ ) yield, respectively. ${ }^{1} \mathrm{H}$ NMR $\left(200 \mathrm{MHz}, \mathrm{CDCl}_{3}\right): \delta 5.14-4.96(\mathrm{~m}$, $1 \mathrm{H}), 2.43-2.25(\mathrm{~m}, 4 \mathrm{H}), 1.96(\mathrm{q}, J=6.5 \mathrm{~Hz}, 2 \mathrm{H}), 1.72-1.59$ (m, 4H), $1.44-1.10(\mathrm{~m}, 8 \mathrm{H}), 0.88(\mathrm{t}, J=6.5 \mathrm{~Hz}, 3 \mathrm{H}) ;{ }^{13} \mathrm{C}\left\{{ }^{1} \mathrm{H}\right\}$ NMR (101 MHz, $\left.\mathrm{CDCl}_{3}\right): \delta 197.2,103.6,91.6,31.9,31.4,29.5$, 29.3, 28.9, 27.2, 22.8, 14.3. HRMS calcd for $\mathrm{C}_{13} \mathrm{H}_{22}\left(\mathrm{M}^{+}\right)$: 178.1722; found: 178.1732 .

4.7.3. Oct-1-en-1-ylidenecycloheptane (5c). Allene 5c was synthesized via procedure A and was obtained as a colorless oil in $50 \%(103 \mathrm{mg})$ yield. ${ }^{1} \mathrm{H} \mathrm{NMR}\left(200 \mathrm{MHz}, \mathrm{CDCl}_{3}\right): \delta 5.00-$ $4.88(\mathrm{~m}, 1 \mathrm{H}), 2.34-2.08(\mathrm{~m}, 4 \mathrm{H}), 1.95(\mathrm{q}, J=6.5 \mathrm{~Hz}, 2 \mathrm{H})$, $1.70-1.45(\mathrm{~m}, 8 \mathrm{H}), 1.44-1.17(\mathrm{~m}, 8 \mathrm{H}), 0.89(\mathrm{t}, J=6.5 \mathrm{~Hz}$, $3 \mathrm{H}) ;{ }^{13} \mathrm{C}\left\{{ }^{1} \mathrm{H}\right\}$ NMR $\left(50 \mathrm{MHz}, \mathrm{CDCl}_{3}\right): \delta 202.0,104.3,88.6$, 32.9, 31.9, 29.5, 29.4, 29.3, 28.9, 28.8, 22.9, 14.3. HRMS calcd for $\mathrm{C}_{15} \mathrm{H}_{26}\left(\mathrm{M}^{+}\right)$: 206.2035; found: 206.2045.

4.7.4. Oct-1-en-1-ylidenecyclododecane (5d). Allene $5 \mathrm{~d}$ was synthesized via procedures $\mathrm{A}$ and $\mathrm{B}$ and was obtained as a colorless oil in $29 \%(80 \mathrm{mg})$ and $50 \%(138 \mathrm{mg})$ yield, respectively. ${ }^{1} \mathrm{H}$ NMR $\left(200 \mathrm{MHz}, \mathrm{CDCl}_{3}\right): \delta 5.09-4.90(\mathrm{~m}$, $1 \mathrm{H}), 2.12-1.82(\mathrm{~m}, 6 \mathrm{H}), 1.61-1.09(\mathrm{~m}, 26 \mathrm{H}), 0.88(\mathrm{t}, J=6.5$ $\mathrm{Hz}, 3 \mathrm{H}) ;{ }^{13} \mathrm{C}\left\{{ }^{1} \mathrm{H}\right\}$ NMR $\left(50 \mathrm{MHz}, \mathrm{CDCl}_{3}\right): \delta 202.24,100.87$, 91.01, 31.92, 29.94, 29.88, 29.66, 29.00, 24.73, 24.59, 24.27, 23.24, 22.82, 22.43, 14.28. HRMS calcd for $\mathrm{C}_{20} \mathrm{H}_{36}\left(\mathrm{M}^{+}\right)$: 276.2817; found: 276.2789 .

4.7.5. 4-Methyldodeca-4,5-diene (5e). Allene 5e was synthesized via procedure $\mathrm{A}$ and was obtained as a colorless oil in $49 \%(88 \mathrm{mg})$ yield. ${ }^{1} \mathrm{H} \mathrm{NMR}\left(200 \mathrm{MHz}, \mathrm{CDCl}_{3}\right): \delta 5.06-$ $4.91(\mathrm{~m}, 1 \mathrm{H}), 2.02-1.82(\mathrm{~m}, 4 \mathrm{H}), 1.66(\mathrm{~d}, J=3.0 \mathrm{~Hz}, 3 \mathrm{H})$, $1.53-1.09(\mathrm{~m}, 10 \mathrm{H}), 1.00-0.73(\mathrm{~m}, 6 \mathrm{H}) ;{ }^{13} \mathrm{C}\left\{{ }^{1} \mathrm{H}\right\}$ NMR $(50$ $\left.\mathrm{MHz}, \mathrm{CDCl}_{3}\right): \delta 201.4,99.1,90.2$, 36.5, 31.9, 29.6, 29.5, 29.0, $22.8,20.9,19.4,14.3$, 14.0. HRMS calcd for $\mathrm{C}_{13} \mathrm{H}_{24}\left(\mathrm{M}^{+}\right)$: 180.1878; found: 180.1898 .

4.7.6. 7-Methylpentadeca-7,8-diene (5f). ${ }^{35 a}$ Allene $\mathbf{5 f}$ was synthesized via procedure $\mathrm{A}$ and was obtained as a colorless oil in $43 \%(96 \mathrm{mg})$ yield. ${ }^{1} \mathrm{H} \mathrm{NMR}\left(200 \mathrm{MHz}^{\mathrm{CDCl}} \mathrm{CDC}_{3}\right): \delta 5.07-$ $4.88(\mathrm{~m}, 1 \mathrm{H}), 2.01-1.85(\mathrm{~m}, 4 \mathrm{H}), 1.66(\mathrm{~d}, J=3.0 \mathrm{~Hz}, 3 \mathrm{H})$, $1.47-1.13(\mathrm{~m}, 16 \mathrm{H}), 0.89(\mathrm{t}, J=6.5 \mathrm{~Hz}, 6 \mathrm{H}) ;{ }^{13} \mathrm{C}\left\{{ }^{1} \mathrm{H}\right\} \mathrm{NMR}$ $\left(50 \mathrm{MHz}, \mathrm{CDCl}_{3}\right): \delta$ 201.3, 99.3, 90.2, 34.3, 32.0, 31.9, 29.6, 29.5, 29.2, 29.0, 27.7, 22.9, 19.5, 14.3 .

4.7.7. 1-Methyl-2-(oct-1-en-1-ylidene)cyclohexane (5g). ${ }^{48}$ Allene $5 \mathrm{~g}$ was synthesized via procedures $\mathrm{A}$ and $\mathrm{B}$ and was obtained as a colorless oil in $35 \%(72 \mathrm{mg})$ and $33 \%(68 \mathrm{mg})$ yield, respectively. ${ }^{1} \mathrm{H}$ NMR $\left(400 \mathrm{MHz}, \mathrm{CDCl}_{3}\right): \delta 5.16-4.97$ $(\mathrm{m}, 1 \mathrm{H}), 2.35-2.18(\mathrm{~m}, 1 \mathrm{H}), 2.06-1.86(\mathrm{~m}, 4 \mathrm{H}), 1.85-1.65$ $(\mathrm{m}, 3 \mathrm{H}), 1.48-1.18(\mathrm{~m}, 10 \mathrm{H}), 1.16-1.00(\mathrm{~m}, 1 \mathrm{H}), 0.96(\mathrm{~d}, J=$ $6.5 \mathrm{~Hz}, 3 \mathrm{H}), 0.88(\mathrm{t}, J=6.5,3 \mathrm{H}) ;{ }^{13} \mathrm{C}\left\{{ }^{1} \mathrm{H}\right\} \mathrm{NMR}(50 \mathrm{MHz}$, $\left.\mathrm{CDCl}_{3}\right): \delta 197.99,108.41,108.02,91.34,91.30,36.60,36.26$, $34.68,34.61,32.47,32.42,31.96,31.94,29.76,29.62,29.58$, $29.27,29.02,29.00,27.89,27.59,26.43,26.38,22.87,22.85$, $19.90,19.87,14.27$.

4.7.8. 1-Methyl-3-(oct-1-en-1-ylidene)cyclohexane (5h). Allene $\mathbf{5 h}$ was synthesized via procedure $\mathrm{B}$ and was obtained as a colorless oil in $54 \%(111 \mathrm{mg})$ yield. ${ }^{1} \mathrm{H} \mathrm{NMR}(400 \mathrm{MHz}$, $\left.\mathrm{CDCl}_{3}\right): \delta 5.00-4.88(\mathrm{~m}, 1 \mathrm{H}), 2.27-2.11(\mathrm{~m}, 2 \mathrm{H}), 2.00-1.85$ $(\mathrm{m}, 3 \mathrm{H}), 1.83-1.47(\mathrm{~m}, 4 \mathrm{H}), 1.47-1.19(\mathrm{~m}, 9 \mathrm{H}), 1.07-0.94$ $(\mathrm{m}, 1 \mathrm{H}), 0.92(\mathrm{~d}, J=6.5 \mathrm{~Hz}, 3 \mathrm{H}), 0.88(\mathrm{t}, J=7.0,3 \mathrm{H}) ;{ }^{13} \mathrm{C}\left\{{ }^{1} \mathrm{H}\right\}$ NMR $\left(101 \mathrm{MHz}, \mathrm{CDCl}_{3}\right): \delta 198.69,198.65,102.16,101.70$, $88.85,88.76,40.15,40.05,34.82,34.65,33.85,33.26,31.91$, $31.49,31.45,29.57,29.43,29.39,29.08,28.85,27.01,26.48$, $22.89,22.84,22.44,22.26,14.27$. HRMS calcd for $\mathrm{C}_{15} \mathrm{H}_{26}\left(\mathrm{M}^{+}\right)$: 206.2035; found: 206.2035 .

4.7.9. 8-(Oct-1-en-1-ylidene)-1,4-dioxaspiro[4.5]decane (5i). Allene 5i was synthesized via procedures $A$ and was obtained as a yellow oil in $37 \%(93 \mathrm{mg})$ yield. ${ }^{1} \mathrm{H}$ NMR (200 $\left.\mathrm{MHz}, \mathrm{CDCl}_{3}\right): \delta 5.06-4.90(\mathrm{~m}, 1 \mathrm{H}), 3.95(\mathrm{~s}, 4 \mathrm{H}), 2.25\left(\mathrm{dt}, J_{1}=\right.$ $\left.7.5 \mathrm{~Hz}, J_{2}=2.0 \mathrm{~Hz}, 4 \mathrm{H}\right), 2.03-1.84(\mathrm{~m}, 2 \mathrm{H}), 1.72(\mathrm{t}, J=6.5 \mathrm{~Hz}$, $4 \mathrm{H}), 1.47-1.08(\mathrm{~m}, 8 \mathrm{H}), 0.87(\mathrm{t}, J=6.5 \mathrm{~Hz}, 3 \mathrm{H}) ;{ }^{13} \mathrm{C}\left\{{ }^{1} \mathrm{H}\right\}$ NMR (50 MHz, $\mathrm{CDCl}_{3}$ ): $\delta 198.7,108.6$, 99.9, 89.4, 64.4, 35.6, 31.9, 29.3, 29.1, 28.9, 28.8, 22.8, 14.2. HRMS calcd for $\mathrm{C}_{16} \mathrm{H}_{26} \mathrm{O}_{2}$ $\left(\mathrm{M}^{+}\right)$: 250.1933; found: 250.1908 .

4.7.10. Pent-1-en-1-ylidenecyclohexane (5j). ${ }^{49}$ Allene 5j was synthesized via procedure $A$, using 5 equiv of 1 -pentyne, and 
was obtained as a colorless oil in $42 \%$ (63 mg) yield. ${ }^{1} \mathrm{H}$ NMR $\left(200 \mathrm{MHz}, \mathrm{CDCl}_{3}\right): \delta 5.02-4.86(\mathrm{~m}, 1 \mathrm{H}), 2.15-2.01(\mathrm{~m}, 4 \mathrm{H})$, $1.92(\mathrm{q}, J=7.0 \mathrm{~Hz}, 2 \mathrm{H}), 1.73-1.18(\mathrm{~m}, 8 \mathrm{H}), 0.91(\mathrm{t}, J=7.0 \mathrm{~Hz}$, $3 \mathrm{H}) ;{ }^{13} \mathrm{C}\left\{{ }^{1} \mathrm{H}\right\} \mathrm{NMR}\left(50 \mathrm{MHz}, \mathrm{CDCl}_{3}\right): \delta 198.5,102.4,88.6$, 32.0, 31.6, 27.7, 26.4, 22.4, 13.7 .

4.7.11. (4-Cyclohexylidenebut-3-en-1-yl)benzene $(5 k){ }^{49}$ Allene 5k was synthesized via procedure $A$ and was obtained as a colorless to yellowish oil in $73 \%(155 \mathrm{mg})$ yield. ${ }^{1} \mathrm{H}$ NMR $\left(200 \mathrm{MHz}, \mathrm{CDCl}_{3}\right): \delta 7.40-7.07(\mathrm{~m}, 5 \mathrm{H}), 5.11-4.93(\mathrm{~m}, 1 \mathrm{H})$, $2.73(\mathrm{t}, J=7.0 \mathrm{~Hz}, 2 \mathrm{H}), 2.43-2.19(\mathrm{~m}, 2 \mathrm{H}), 2.19-1.95(\mathrm{~m}$, $4 \mathrm{H}), 1.73-1.35(\mathrm{~m}, 6 \mathrm{H}) ;{ }^{13} \mathrm{C}\left\{{ }^{1} \mathrm{H}\right\} \operatorname{NMR}\left(50 \mathrm{MHz} \mathrm{CDCl}_{3}\right): \delta$ 198.6, 142.3, 128.6, 128.3, 125.8, 103.1, 88.2, 35.5, 31.8, 31.1, $27.6,26.3$.

4.7.12. (3-Cyclohexylideneallyl)benzene (5I). ${ }^{50}$ Allene $\mathbf{5 1}$ was synthesized via procedure A and was obtained as a colorless to yellowish oil in $18 \%$ (36 mg) yield. ${ }^{1} \mathrm{H}$ NMR (200 MHz, $\left.\mathrm{CDCl}_{3}\right): \delta 7.39-7.10(\mathrm{~m}, 5 \mathrm{H}), 5.23-5.04(\mathrm{~m}, 1 \mathrm{H}), 3.32(\mathrm{~d}, J=$ $7.0 \mathrm{~Hz}, 2 \mathrm{H}), 2.21-1.98(\mathrm{~m}, 4 \mathrm{H}), 1.71-1.35(\mathrm{~m}, 6 \mathrm{H}) ;{ }^{13} \mathrm{C}\left\{{ }^{1} \mathrm{H}\right\}$ NMR $\left(101 \mathrm{MHz}, \mathrm{CDCl}_{3}\right): \delta 199.3,141.2,128.8,128.4,126.0$, 103.2, 88.5, 36.5, 31.8, 27.5, 26.3.

4.7.13. (3-Cyclohexylideneallyl)cyclohexane (5m). Allene $\mathbf{5 m}$ was synthesized via procedure $A$ and was obtained as a colorless to yellowish oil in $45 \%$ (92 mg) yield. ${ }^{1} \mathrm{H}$ NMR (200 $\left.\mathrm{MHz} \mathrm{CDCl}_{3}\right): \delta 4.99-4.80(\mathrm{~m}, 1 \mathrm{H}), 2.23-1.93(\mathrm{~m}, 4 \mathrm{H}), 1.84$ $(\mathrm{t}, J=7.0 \mathrm{~Hz}, 2 \mathrm{H}), 1.77-1.43(\mathrm{~m}, 11 \mathrm{H}), 1.39-1.03(\mathrm{~m}, 4 \mathrm{H})$, $1.03-0.78(\mathrm{~m}, 2 \mathrm{H}) ;{ }^{13} \mathrm{C}\left\{{ }^{1} \mathrm{H}\right\} \mathrm{NMR}\left(50 \mathrm{MHz}, \mathrm{CDCl}_{3}\right): \delta 198.9$, 101.7, 87.2, 38.1, 37.7, 33.2, 32.0, 27.7, 26.8, 26.5, 26.4. HRMS calcd for $\mathrm{C}_{15} \mathrm{H}_{26}\left(\mathrm{M}^{+}\right)$: 204.1878; found: 204.1883 .

4.7.14. 2-(3-Cyclohexylideneallyl)isoindoline-1,3-dione $(5 n) .{ }^{35 b}$ Allene $5 n$ was synthesized via procedure A and was obtained as a white solid in $51 \%(136 \mathrm{mg})$ yield. ${ }^{1} \mathrm{H}$ NMR (200 $\left.\mathrm{MHz}, \mathrm{CDCl}_{3}\right): \delta 7.92-7.79(\mathrm{~m}, 2 \mathrm{H}), 7.78-7.65(\mathrm{~m}, 2 \mathrm{H})$, 5.10-4.97 $(\mathrm{m}, 1 \mathrm{H}), 4.27(\mathrm{~d}, J=4.5 \mathrm{~Hz}, 2 \mathrm{H}), 2.05-1.81(\mathrm{~m}$, $4 \mathrm{H}), 1.55-1.37(\mathrm{~m}, 2 \mathrm{H}), 1.34-1.21(\mathrm{~m}, 2 \mathrm{H}), 1.10-0.91(\mathrm{~m}$, $2 \mathrm{H}) ;{ }^{13} \mathrm{C}\left\{{ }^{1} \mathrm{H}\right\}$ NMR (50 MHz, $\left.\mathrm{CDCl}_{3}\right): \delta$ 197.6, 168.0, 134.0, 132.4, 123.3, 107.0, 84.5, 37.1, 31.1, 27.0, 25.8.

4.7.15. N-(3-Cyclohexylideneallyl)benzamide (50). ${ }^{51}$ Allene 5o was synthesized via procedure $A$ and was obtained as an orange solid in $32 \%(77 \mathrm{mg})$ yield. ${ }^{1} \mathrm{H}$ NMR $(400 \mathrm{MHz}$, $\left.\mathrm{CDCl}_{3}\right): \delta 7.77(\mathrm{~d}, J=7.5 \mathrm{~Hz}, 2 \mathrm{H}), 7.47(\mathrm{t}, J=7.5 \mathrm{~Hz}, 1 \mathrm{H}), 7.41$ $(\mathrm{t}, J=7.5 \mathrm{~Hz}, 2 \mathrm{H}), 6.37(\mathrm{~s}, 1 \mathrm{H}), 5.20-5.11(\mathrm{~m}, 1 \mathrm{H}), 3.97(\mathrm{t}, J=$ $5.0 \mathrm{~Hz}, 2 \mathrm{H}), 2.20-2.03(\mathrm{~m}, 4 \mathrm{H}), 1.67-1.38(\mathrm{~m}, 6 \mathrm{H}) ;{ }^{13} \mathrm{C}\left\{{ }^{1} \mathrm{H}\right\}$ NMR (50 MHz, $\left.\mathrm{CDCl}_{3}\right): \delta 197.5,167.3,134.7,131.5,128.6$, 126.9, 106.5, 86.5, 38.9, 31.5, 27.5, 26.0. HRMS calcd for $\mathrm{C}_{16} \mathrm{H}_{19} \mathrm{NO}\left(\mathrm{M}^{+}\right)$: 241.1467; found: 241.1448.

4.7.16. 4-Cyclohexylidene-1-phenylbut-3-en-1-ol (5p). Allene $5 p$ was synthesized via procedure $A$ and was obtained as a yellowish oil in $38 \%(87 \mathrm{mg})$ yield. ${ }^{1} \mathrm{H}$ NMR (400 MHz, $\left.\mathrm{CDCl}_{3}\right): \delta 7.43-7.23(\mathrm{~m}, 5 \mathrm{H}), 5.04-4.92(\mathrm{~m}, 1 \mathrm{H}), 4.76(\mathrm{t}, J=$ $6.5 \mathrm{~Hz}, 1 \mathrm{H}), 2.49-2.38(\mathrm{~m}, 2 \mathrm{H}), 2.35-2.27(\mathrm{~m}, 1 \mathrm{H}), 2.17-$ $2.01(\mathrm{~m}, 4 \mathrm{H}), 1.65-1.46(\mathrm{~m}, 6 \mathrm{H}) ;{ }^{13} \mathrm{C}\left\{{ }^{1} \mathrm{H}\right\} \mathrm{NMR}(101 \mathrm{MHz}$, $\left.\mathrm{CDCl}_{3}\right): \delta 200.0,143.9,128.4,127.5,126.1,103.2,84.7,73.7$, 39.7, 31.8, 31.6, 27.5, 26.2. HRMS calcd for $\mathrm{C}_{16} \mathrm{H}_{20} \mathrm{O}\left(\mathrm{M}^{+}\right)$: 228.1514; found: 228.1502 .

4.7.17. 1-(4-Bromophenyl)-4-cyclohexylidenebut-3-en-1ol $(5 q)$. Allene $\mathbf{5 q}$ was synthesized via procedure A and was obtained as a yellowish oil in $35 \%$ (108 mg) yield. ${ }^{1} \mathrm{H}$ NMR (200 $\left.\mathrm{MHz}, \mathrm{CDCl}_{3}\right): \delta 7.46(\mathrm{~d}, J=8.0 \mathrm{~Hz}, 2 \mathrm{H}), 7.24(\mathrm{~d}, J=8.0 \mathrm{~Hz}$, $2 \mathrm{H}), 5.02-4.85(\mathrm{~m}, 1 \mathrm{H}), 4.71(\mathrm{t}, J=6.5 \mathrm{~Hz}, 1 \mathrm{H}), 2.52-2.22$ (m, 2H), 2.18-1.91 (m, 4H), $1.77-1.37(\mathrm{~m}, 6 \mathrm{H}) ;{ }^{13} \mathrm{C}\left\{{ }^{1} \mathrm{H}\right\}$ $\mathrm{NMR}\left(50 \mathrm{MHz}, \mathrm{CDCl}_{3}\right): \delta$ 200.0, 142.9, 131.5, 127.9, 121.2, 103.4, 84.3, 73.0, 39.7, 31.7, 31.6, 27.4, 26.1. HRMS calcd for $\mathrm{C}_{16} \mathrm{H}_{19} \mathrm{BrO}\left(\mathrm{M}^{+}\right)$: 306.0619; found: 306.0604 .
4.7.18. 1-(4-Bromophenyl)-4-(1,4-dioxaspiro[4.5]decan-8ylidene)but-3-en-1-ol (5r). Allene $5 \mathbf{r}$ was synthesized via procedure $\mathrm{A}$, at a $0.8 \mathrm{mmol}$ scale, and was obtained as a yellow oil in 26\% (95 mg) yield. ${ }^{1} \mathrm{H}$ NMR (200 MHz, $\left.\mathrm{CDCl}_{3}\right): \delta 7.45$ $(\mathrm{d}, \mathrm{J}=8.0 \mathrm{~Hz}, 2 \mathrm{H}), 7.22(\mathrm{~d}, J=8.0 \mathrm{~Hz}, 2 \mathrm{H}), 5.04-4.85(\mathrm{~m}, 1 \mathrm{H})$, $4.78-4.56(\mathrm{~m}, 1 \mathrm{H}), 3.94(\mathrm{~s}, 4 \mathrm{H}), 2.46-2.27(\mathrm{~m}, 3 \mathrm{H}), 2.27-$ $2.07(\mathrm{~m}, 4 \mathrm{H}), 1.81-1.58(\mathrm{~m}, 4 \mathrm{H}) ;{ }^{13} \mathrm{C}\{1 \mathrm{H}\} \mathrm{NMR}(50 \mathrm{MHz}$, $\left.\mathrm{CDCl}_{3}\right): \delta 200.3,142.8,131.5,127.9,121.3,108.3,100.6,84.8$, 73.1, 64.4, 39.5, 35.3, 28.6, 28.5. HRMS calcd for $\mathrm{C}_{18} \mathrm{H}_{21} \mathrm{BrO}_{3}$ $\left(\mathrm{M}^{+}\right)$: 364.0674; found: 364.0692 .

4.7.19. (5-Methylocta-3,4-dien-1-yl)benzene (5s). Allene 5s was synthesized via procedure $\mathrm{A}$ and was obtained as a yellowish oil in $60 \%(120 \mathrm{mg})$ yield. ${ }^{1} \mathrm{H} \mathrm{NMR}\left(200 \mathrm{MHz}^{\mathrm{CDCl}} \mathrm{CDC}_{3}\right): \delta$ $7.41-7.03(\mathrm{~m}, 5 \mathrm{H}), 5.17-4.96(\mathrm{~m}, 1 \mathrm{H}), 2.73(\mathrm{t}, J=7.5 \mathrm{~Hz}$, $2 \mathrm{H}), 2.42-2.19(\mathrm{~m}, 2 \mathrm{H}), 1.90\left(\mathrm{dt}, J_{1}=7 \mathrm{~Hz}, J_{2}=3 \mathrm{~Hz}, 2 \mathrm{H}\right), 1.64$ $(\mathrm{d}, J=3 \mathrm{~Hz}, 3 \mathrm{H}), 1.56-1.24(\mathrm{~m}, 2 \mathrm{H}), 0.91(\mathrm{t}, J=7.5 \mathrm{~Hz}, 3 \mathrm{H})$; ${ }^{13} \mathrm{C}\left\{{ }^{1} \mathrm{H}\right\} \mathrm{NMR}\left(50 \mathrm{MHz}, \mathrm{CDCl}_{3}\right): \delta 201.6,142.3,128.7,128.3$, 125.8, 99.8, 89.5, 36.4, 35.8, 31.2, 20.9, 19.3, 14.0. HRMS calcd for $\mathrm{C}_{15} \mathrm{H}_{20}\left(\mathrm{M}^{+}\right): 200.1565$; found: 200.1564 .

4.7.20. 8-(4-Phenylbut-1-en-1-ylidene)-1,4-dioxaspiro[4.5]decane (5t). Allene $5 t$ was synthesized via procedures A and $\mathrm{B}$, using 1.6 equiv for alkyne 4-phenyl-1-butyne and pyrrolidine 1, and was obtained as a yellow oil in $70 \%(189 \mathrm{mg})$ and $72 \%(195 \mathrm{mg})$ yield, respectively. ${ }^{1} \mathrm{H}$ NMR $(200 \mathrm{MHz}$, $\left.\mathrm{CDCl}_{3}\right): \delta 7.35-7.09(\mathrm{~m}, 5 \mathrm{H}), 5.11-4.95(\mathrm{~m}, 1 \mathrm{H}), 3.95(\mathrm{~s}$, $3 \mathrm{H}), 2.72(\mathrm{t}, J=7.0 \mathrm{~Hz}, 2 \mathrm{H}), 2.39-2.09(\mathrm{~m}, 6 \mathrm{H}), 1.77-1.59$ $(\mathrm{m}, 4 \mathrm{H}) ;{ }^{13} \mathrm{C}\left\{{ }^{1} \mathrm{H}\right\}$ NMR $\left(50 \mathrm{MHz}, \mathrm{CDCl}_{3}\right): \delta 198.9,142.0$, 128.6, 128.3, 125.8, 108.5, 100.5, 88.7, 64.4, 35.5, 35.4, 30.8, 28.7. HRMS calcd for $\mathrm{C}_{18} \mathrm{H}_{22} \mathrm{O}_{2}\left(\mathrm{M}^{+}\right)$: 270.1620; found: 270.1594 .

4.7.21. 2-(3-Cyclododecylideneallyl)isoindoline-1,3-dione (5u). Allene $\mathbf{5 u}$ was synthesized via procedure B and was obtained as a white-yellow solid in $46 \%(162 \mathrm{mg})$ yield. ${ }^{1} \mathrm{H}$ $\mathrm{NMR}\left(200 \mathrm{MHz}, \mathrm{CDCl}_{3}\right): \delta 7.92-7.61(\mathrm{~m}, 4 \mathrm{H}), 5.25-5.07(\mathrm{~m}$, $1 \mathrm{H}), 4.26(\mathrm{~d}, J=5.0 \mathrm{~Hz}, 2 \mathrm{H}), 2.02-1.75(\mathrm{~m}, 4 \mathrm{H}), 1.49-0.81$ $(\mathrm{m}, 18 \mathrm{H}) ;{ }^{13} \mathrm{C}\left\{{ }^{1} \mathrm{H}\right\}$ NMR $\left(50 \mathrm{MHz}, \mathrm{CDCl}_{3}\right): \delta 201.5,168.0$, 134.0, 132.5, 123.3, 106.1, 86.8, 36.9, 29.5, 24.6, 24.2, 24.1, 23.4, 22.5. HRMS calcd for $\mathrm{C}_{23} \mathrm{H}_{29} \mathrm{NO}_{2}\left(\mathrm{M}^{+}\right)$: 351.2198; found: 351.2192 .

4.7.22. 2-(4-Methylhepta-2,3-dien-1-yl)isoindoline-1,3dione $(5 \mathrm{v})$. Allene $\mathbf{5 v}$ was synthesized via procedure $\mathrm{B}$ and was obtained as a yellow oil in $51 \%(130 \mathrm{mg})$ yield. ${ }^{1} \mathrm{H}$ NMR $\left(200 \mathrm{MHz}, \mathrm{CDCl}_{3}\right): \delta 7.89-7.78(\mathrm{~m}, 2 \mathrm{H}), 7.75-7.66(\mathrm{~m}, 2 \mathrm{H})$, $5.16-5.01(\mathrm{~m}, 1 \mathrm{H}), 4.24(\mathrm{~d}, J=4.0 \mathrm{~Hz}, 2 \mathrm{H}), 1.83-1.68(\mathrm{~m}$, $2 \mathrm{H}), 1.53(\mathrm{~d}, J=3.0 \mathrm{~Hz}, 3 \mathrm{H}), 1.38-1.10(\mathrm{~m}, 3 \mathrm{H}), 0.79(\mathrm{t}, J=7.0$ $\mathrm{Hz}, 3 \mathrm{H}) ;{ }^{13} \mathrm{C}\left\{{ }^{1} \mathrm{H}\right\}$ NMR $\left(101 \mathrm{MHz}, \mathrm{CDCl}_{3}\right): \delta 201.3,169.2$, 134.6, 132.4, 122.9, 103.6, 85.4, 37.3, 36.4, 20.6, 18.7, 13.9. HRMS calcd for $\mathrm{C}_{16} \mathrm{H}_{17} \mathrm{NO}_{2}\left(\mathrm{M}^{+}\right): 255.1259$; found: 255.1233 .

4.7.23. 2-(4-Methyldeca-2,3-dien-1-yl)isoindoline-1,3dione $(5 w)$. Allene $5 \mathrm{w}$ was synthesized via procedure $\mathrm{B}$ and was obtained as a white-yellow solid in $62 \%(184 \mathrm{mg})$ yield. ${ }^{1} \mathrm{H}$ $\mathrm{NMR}\left(200 \mathrm{MHz}, \mathrm{CDCl}_{3}\right): \delta 7.91-7.63(\mathrm{~m}, 4 \mathrm{H}), 5.18-5.00(\mathrm{~m}$, $1 \mathrm{H}), 4.24(\mathrm{~d}, J=5.0 \mathrm{~Hz}, 2 \mathrm{H}), 1.84-1.69(\mathrm{~m}, 2 \mathrm{H}), 1.54(\mathrm{~d}, J=$ $3.0 \mathrm{~Hz}, 3 \mathrm{H}), 1.34-1.02(\mathrm{~m}, 8 \mathrm{H}), 0.83(\mathrm{~d}, J=6.5,3 \mathrm{H}) ;{ }^{13} \mathrm{C}\left\{{ }^{1} \mathrm{H}\right\}$ $\mathrm{NMR}\left(50 \mathrm{MHz}, \mathrm{CDCl}_{3}\right): \delta 201.1,167.9,133.9,132.3,123.2$, 103.8, 85.8, 37.2, 33.8, 31.7, 29.0, 27.3, 22.6, 18.7, 14.2. HRMS calcd for $\mathrm{C}_{19} \mathrm{H}_{23} \mathrm{NO}_{2}\left(\mathrm{M}^{+}\right)$: 297.1729; found: 297.1701 .

4.7.24. 2-(3-(3-Methylcyclohexylidene)allyl)isoindoline1,3 -dione $(5 x)$. Allene $5 \mathbf{x}$ was synthesized via procedure $B$ and was obtained as a white-yellowish paste in $44 \%(123 \mathrm{mg})$ yield. ${ }^{1} \mathrm{H}$ NMR (200 MHz, $\mathrm{CDCl}_{3}$ ): $\delta 7.93-7.62(\mathrm{~m}, 4 \mathrm{H}), 5.11-4.96$ $(\mathrm{m}, 1 \mathrm{H}), 4.32-4.16(\mathrm{~m}, 2 \mathrm{H}), 2.20-1.98(\mathrm{~m}, 2 \mathrm{H}), 1.77-1.10$ $(\mathrm{m}, 6 \mathrm{H}), 0.97-0.68(\mathrm{~m}, 4 \mathrm{H}) ;{ }^{13} \mathrm{C}\left\{{ }^{1} \mathrm{H}\right\} \mathrm{NMR}(101 \mathrm{MHz}$, 
$\left.\mathrm{CDCl}_{3}\right): \delta 198.52,197.78,167.99,167.92,133.99,133.97$, $132.52,132.42,123.23,106.78,105.89,84.63,84.37,39.17$, $39.05,37.40,37.04,34.35,34.29,33.29,33.02,30.65,30.60$, 26.40, 26.13, 22.31, 22.03. HRMS calcd for $\mathrm{C}_{18} \mathrm{H}_{19} \mathrm{NO}_{2}\left(\mathrm{M}^{+}\right)$: 281.1416; found: 281.1391 .

4.7.25. 2-(3-(1,4-Dioxaspiro[4.5]decan-8-ylidene)allyl)isoindoline-1,3-dione (5y). Allene 5y was synthesized via procedure A, using 1.6 equiv of pyrrolidine 1 , and was obtained as a white-yellowish solid in $51 \%(166 \mathrm{mg})$ yield. ${ }^{1} \mathrm{H}$ NMR (200 $\left.\mathrm{MHz} \mathrm{CDCl}_{3}\right): \delta 7.91-7.62(\mathrm{~m}, 4 \mathrm{H}), 5.13-5.00(\mathrm{~m}, 1 \mathrm{H}), 4.25$ $(\mathrm{d}, J=4.5 \mathrm{~Hz}, 2 \mathrm{H}), 3.84(\mathrm{~s}, 4 \mathrm{H}), 2.26-1.99(\mathrm{~m}, 4 \mathrm{H}), 1.65-1.45$ $(\mathrm{m}, 2 \mathrm{H}), 1.33-1.09(\mathrm{~m}, 2 \mathrm{H}) ;{ }^{13} \mathrm{C}\left\{{ }^{1} \mathrm{H}\right\}$ NMR $(50 \mathrm{MHz}$, $\left.\mathrm{CDCl}_{3}\right): \delta 198.0,167.9,134.1,132.3,123.3,108.0,104.4,85.2$, 64.3, 37.0, 34.9, 28.1. HRMS calcd for $\mathrm{C}_{19} \mathrm{H}_{19} \mathrm{NO}_{4}\left(\mathrm{M}^{+}\right)$: 325.1314; found: 325.1294 .

\section{ASSOCIATED CONTENT}

\section{SI Supporting Information}

The Supporting Information is available free of charge at https://pubs.acs.org/doi/10.1021/acsomega.1c03092.

Spectroscopic data for compounds 5, 5a-D, and 12; computational methods and Cartesian coordinates (PDF)

\section{AUTHOR INFORMATION}

\section{Corresponding Author}

Georgios C. Vougioukalakis - Laboratory of Organic Chemistry, Department of Chemistry, National and Kapodistrian University of Athens, 15771 Athens, Greece; 이이.org/0000-0002-4620-5859; Email: vougiouk@ chem.uoa.gr

\section{Authors}

Leandros P. Zorba - Laboratory of Organic Chemistry, Department of Chemistry, National and Kapodistrian University of Athens, 15771 Athens, Greece

Eunate Egaña - Department of Organic Chemistry I, Faculty of Chemistry, University of the Basque Country UPV/EHU, 20018 Donostia-San Sebastián, Spain

Enrique Gómez-Bengoa - Department of Organic Chemistry I, Faculty of Chemistry, University of the Basque Country UPV/ EHU, 20018 Donostia-San Sebastián, Spain; ㅈorcid.org/ 0000-0002-8753-3760

Complete contact information is available at:

https://pubs.acs.org/10.1021/acsomega.1c03092

\section{Notes}

The authors declare no competing financial interest.

\section{ACKNOWLEDGMENTS}

The research project was supported by the Hellenic Foundation for Research and Innovation (H.F.R.I.) under the " $1{ }^{\text {st }}$ Call for H.F.R.I. Research Projects to support Faculty Members \& Researchers and the procurement of high-cost research equipment grant" (Project Number: 16-Acronym: SUSTAIN). We thank Professor Thomas Mavromoustakos for his advice and support concerning the calculation of the relaxation delay times for the NMR analysis related to the kinetic isotope effect measurements. We also acknowledge the contribution of COST Action CA15106 (C-H Activation in Organic Synthesis-CHAOS). We also thank the Spanish Ministerio de Ciencia e Innovación (PID2019-110008GB-I00) and IZO-SGI
SGIker of UPV/EHU for financial and human support. The Special Account for Research Grants of the National and Kapodistrian University of Athens is also gratefully acknowledged for funding (research program 70/4/17454).

\section{REFERENCES}

(1) (a) Taylor, D. R. The Chemistry of Allenes. Chem. Rev. 1967, 67, 317-359. (b) Hoffmann-Röder, A.; Krause, N. Synthesis and Properties of Allenic Natural Products and Pharmaceuticals. Angew. Chem., Int. Ed. 2004, 43, 1196-1216. (c) Krause, N.; Hashmi, A. S. K. Modern Allene Chemistry; Wiley-VCH, Verlag GmbH: Weinheim, Germany, 2004. (d) Brummond, K. M. Allene Chemistry. Beilstein J. Org. Chem. 2011, 7, 394-395. (e) Krause, N.; Winter, C. GoldCatalyzed Nucleophilic Cyclization of Functionalized Allenes: A Powerful Access to Carbo-and Heterocycles. Chem. Rev. 2011, 111, 1994-2009. (f) Yu, S.; Ma, S. Allenes in Catalytic Asymmetric Synthesis and Natural Product Syntheses. Angew. Chem., Int. Ed. 2012, 51, 3074-3112. (g) Soriano, E.; Fernández, I. Allenes and Computational Chemistry: From Bonding Situations to Reaction Mechanisms. Chem. Soc. Rev. 2014, 43, 3041-3105.

(2) (a) Ohno, H.; Chiba, H.; Inuki, S.; Oishi, S.; Fujii, N. The Synthesis of Alkaloids Using Transition-Metal-Catalyzed Intramolecular Amination Reactions. Synlett 2014, 25, 179-192. (b) Reissig, H. U.; Zimmer, R. Allenes in Multicomponent Synthesis of Heterocycles. Multicomponent Reactions in Organic Synthesis; Wiley-VCH Verlag GmbH: Weinheim, Germany, 2014; pp 301-332. (c) Alonso, J. M.; $\mathrm{Paz}, \mathrm{M}$. When Indoles Meet Allene and Its Derivatives. Eur. J. Org. Chem. 2020, 7197-7213. (d) Fernandes, R. A.; Pathare, R. S.; Gorve, D. A. Advances in Total Synthesis of Some 2, 3, 5-Trisubstituted Tetrahydrofuran Natural Products. Chem. Asian J. 2020, 2815-2837.

(3) (a) Lechel, T.; Pfrengle, F.; Reissig, H. U.; Zimmer, R. Three Carbons for Complexity! Recent Developments of PalladiumCatalyzed Reactions of Allenes. ChemCatChem 2013, 5, 2100-2130. (b) López, F.; Mascareñas, J. L. And [4+3] Catalytic Cycloadditions of Allenes. Chem. Soc. Rev. 2014, 43, 2904-2915. (c) Kitagaki, S.; Inagaki, F.; Mukai, C. Cyclization of Allenes. Chem. Soc. Rev. 2014, 43, 29562978. (d) Alcaide, B.; Almendros, P.; Aragoncillo, C. Cyclization Reactions of Bis(Allenes) for the Synthesis of Polycarbo(Hetero)Cycles. Chem. Soc. Rev. 2014, 43, 3106-3135. (e) Adams, C. S.; Weatherly, C. D.; Burke, E. G.; Schomaker, J. M. The Conversion of Allenes to Strained Three-Membered Heterocycles. Chem. Soc. Rev. 2014, 43, 3136-3163. (f) Lledó, A.; Pla-Quintana, A.; Roglans, A. Allenes, Versatile Unsaturated Motifs in Transition-Metal-Catalysed [2+2+2] Cycloaddition Reactions. Chem. Soc. Rev. 2016, 45, 20102023. (g) Swamy, K. C. K.; Anitha, M.; Gangadhararao, G.; Rama Suresh, R. Exploring Allene Chemistry Using Phosphorus-Based Allenes as Scaffolds. Pure Appl. Chem. 2017, 89, 367-377. (h) Santhoshkumar, R.; Cheng, C. H. Fickle Reactivity of Allenes in Transition-Metal-Catalyzed $\mathrm{C}-\mathrm{H}$ Functionalizations. Asian J. Org. Chem. 2018, 7, 1151-1163. (i) Holmes, M.; Schwartz, L. A.; Krische, M. J. Intermolecular Metal-Catalyzed Reductive Coupling of Dienes, Allenes, and Enynes with Carbonyl Compounds and Imines. Chem. Rev. 2018, 118, 6026-6052. (j) Michalak, M.; Kosni, W. Chiral N -Heterocyclic Carbene Gold Complexes: Synthesis and Applications in Catalysis. Catalysts 2019, 9, No. 890. (k) Zhang, W.; Guanlin, L.; Huo, X.; Xieyang, J. Asymmetric Synthesis of Allylic Compounds via Hydrofunctionalisation and Difunctionalisation of Dienes, Allenes, and Alkynes. Chem. Soc. Rev. 2020, 49, 2060-2118. (1) Lozovskiy, S. V. Synthesis of Heterocycles from Allenes Containing Electron-Withdrawing Substituents under the Conditions of Electrophilic Activation: Recent Advances. Chem. Heterocycl. Compd. 2020, 56, 848-853. (m) Cadierno, V. Gold-Catalyzed Addition of Carboxylic Acids to Alkynes and Allenes: Valuable Tools for Organic Synthesis. Catalysts 2020, 10, 1-37. (n) Hoveyda, A. H.; Zhou, Y.; Shi, Y.; Brown, M. K.; $\mathrm{Wu}, \mathrm{H}$.; Torker, S. Sulfonate N-Heterocyclic Carbene-Copper Complexes: Uniquely Effective Catalysts for Enantioselective Synthesis of $\mathrm{C}-\mathrm{C}, \mathrm{C}-\mathrm{B}, \mathrm{C}-\mathrm{H}$, and $\mathrm{C}-\mathrm{Si}$ Bonds. Angew. Chem., Int. Ed. 2020, 59, 21304-21359. 
(4) (a) Yang, Y.; Petersen, J. L.; Wang, K. K. Polycyclic Aromatic Compounds via Radical Cyclizations of Benzannulated Enyne-Allenes Derived from Ireland-Claisen Rearrangement. J. Org. Chem. 2003, 68, 8545-8549. (b) Brummond, K. M.; You, L. Consecutive Rh(I)Catalyzed Alder-Ene/Diels-Alder/Diels-Alder Reaction Sequence Affording Rapid Entry to Polycyclic Compounds. Tetrahedron 2005, 61, 6180-6185. (c) Luzung, M. R.; Mauleón, P.; Toste, F. D. Gold(I)Catalyzed [2 + 2]-Cycloaddition of Allenenes. J. Am. Chem. Soc. 2007, 129, 12402-12403. (d) Krause, N.; Aksin-Artok, Ö.; Breker, V.; Deutsch, C.; Gockel, B.; Poonoth, M.; Sawama, Y.; Sawama, Y.; Sun, T.; Winter, C. Combined Coinage Metal Catalysis for the Synthesis of Bioactive Molecules. Pure Appl. Chem. 2010, 82, 1529-1536. (e) Boobalan, R.; Kuppusamy, R.; Santhoshkumar, R.; Gandeepan, P.; Cheng, C. H. Access to Isoquinolin-1 $(2 \mathrm{H})$-Ones and Pyridones by Cobalt-Catalyzed Oxidative Annulation of Amides with Allenes. ChemCatChem 2017, 9, 273-277. (f) Han, Y.; Ma, S. RhodiumCatalyzed Highly Diastereoselective Intramolecular $[4+2]$ Cycloaddition of 1,3-Disubstituted Allene-1,3-Dienes. Org. Chem. Front. 2018, 5, 2680-2684. (g) Huang, W.; Zhang, Y. C.; Jin, R.; Chen, B. L.; Chen, Z. Synthesis of Axially Chiral 1,2,3-Triazol-5-Ylidene-Au(I) Complex and Its Application in Enantioselective [2+2] Cycloaddition of Alleneamides with Alkenes. Organometallics 2018, 37, 3196-3209. (h) Sala, R.; Broggini, G. Palladium-Catalyzed Domino Carbopalladation/Cyclization of Allenes. Targets Heterocycl. Syst. 2018, 22, 139164. (i) Yu, S.; Vermeeren, P.; van Dommelen, K.; Bickelhaupt, F. M.; Hamlin, T. A. Understanding the 1,3-Dipolar Cycloadditions of Allenes. Chem. - Eur. J. 2020, 26, 11529-11539. (j) Nelson, R.; Calvelo, M.; García-Fandiño, R.; Lledós, A.; Ujaque, G.; Mascareñas, J. L.; López, F. Skeletal Diversity in Pt- And Au-Catalyzed Annulations of Allenedienes: Dissecting Unconventional Mechanistic Pathways. Chem. Sci. 2020, 11, 4209-4220. (k) Jadhav, P.; Chen, J.; Liu, R.; Jadhav, P. D.; Chen, J.; Liu, R. Letterof Cyclopentadienes with Nitrosoarenes via Nitroso- Povarov versus OxidativeNitroso-Povarov Reactions Gold (I) -Catalyzed Highly Enantioselective $[4+2]$-Annulations of $\mathrm{Cy}$ Clopentadienes with Nitrosoarenes via Nitroso-Povarovversus OxiDat. 2020, No. I.

(5) (a) Nakanowatari, S.; Mei, R.; Feldt, M.; Ackermann, L. Cobalt(III)-Catalyzed Hydroarylation of Allenes via C-H Activation. ACS Catal. 2017, 7, 2511-2515. (b) Han, X.; Lin, P.; Li, Q. Recent Advances of Allenes in the First-Row Transition Metals Catalyzed C-H Activation Reactions. Chin. Chem. Lett. 2019, 30, 1495-1502.

(6) (a) Alcaide, B.; Almendros, P. Novel Cyclization Reactions of Aminoallenes. Adv. Synth. Catal. 2011, 353, 2561-2576. (b) Regás, D.; Afonso, M. M.; Palenzuela, J. A. Pyridines and Pyridine Derivatives from Vinyl Allenes and Imines. Tetrahedron 2012, 68, 9345-9349. (c) Kim, H.; Rhee, Y. H. Stereodefined N,O-Acetals: Pd-Catalyzed Synthesis from Homopropargylic Amines and Utility in the Flexible Synthesis of 2,6-Substituted Piperidines. J. Am. Chem. Soc. 2012, 134, 4011-4014. (d) Thieme, N.; Breit, B. Enantioselective and Regiodivergent Addition of Purines to Terminal Allenes: Synthesis of Abacavir. Angew. Chem., Int. Ed. 2017, 56, 1520-1524. (e) Bernar, I.; Fiser, B.; Blanco-Ania, D.; Gómez-Bengoa, E.; Rutjes, F. P. J. T. PdCatalyzed Hydroamination of Alkoxyallenes with Azole Heterocycles: Examples and Mechanistic Proposal. Org. Lett. 2017, 19, 4211-4214. (f) Schmidt, J. P.; Breit, B. Transition Metal Catalyzed Stereodivergent Synthesis of: syn- and anti- $\delta$-Vinyl-lactams: Formal Total Synthesis of (-)-Cermizine C and (-)-Senepodine G. Chem. Sci. 2019, 10, 30743079.

(7) (a) Amako, Y.; Arai, S.; Nishida, A. Transfer of Axial Chirality through the Nickel-Catalysed Hydrocyanation of Chiral Allenes. Org. Biomol. Chem. 2017, 15, 1612-1617. (b) Hori, H.; Arai, S.; Nishida, A. Olefin-Migrative Cleavage of Cyclopropane Rings through the NickelCatalyzed Hydrocyanation of Allenes and Alkenes. Adv. Synth. Catal. 2017, 359, 1170-1176. (c) Long, J.; Gao, J.; Fang, X. Nickel-Catalyzed Asymmetric Hydrocyanation of Allenes. Org. Lett. 2020, 22, 376-380. (8) (a) Zhang, Z.; Widenhoefer, R. A. Regio- And Stereoselective Synthesis of Alkyl Allylic Ethers via Gold(1)-Catalyzed Intermolecular Hydroalkoxylation of Allenes with Alcohols. Org. Lett. 2008, 10, 20792081. (b) Webster, S.; Sutherland, D. R.; Lee, A.-L. Chirality Transfer in
Gold(I)-Catalysed Hydroalkoxylation of 1,3-Disubstituted Allenes. Chem. - Eur. J. 2016, 22, 18593-18600. (c) Tsukamoto, H.; Ito, K.; Doi, T. Synthesis of Multi-Substituted Dihydrofurans via PalladiumCatalysed Coupling between 2,3-Alkadienols and Pronucleophiles. Chem. Commun. 2018, 54, 5102-5105. (d) Li, Z.; Xie, W.-B. Asymmetric Synthesis of Ethers by Catalytic Alkene Hydroalkoxylation. Synthesis 2020, 52, No. 2127.

(9) (a) Tao, X.; Daniliuc, C. G.; Dittrich, D.; Kehr, G.; Erker, G. Borane-Induced Dimerization of Arylallenes. Angew. Chem., Int. Ed. 2018, 57, 13922-13926. (b) Nagashima, Y.; Sasaki, K.; Suto, T.; Sato, T.; Chida, N. Stereodivergent Hydroboration of Allenes. Chem. Asian J. 2018, 13, 1024-1028. (c) Qin, A.; Qian, H.; Chen, Q.; Ma, S. Palladium-Catalyzed Coupling of Propargylic Alcohols with Boronic Acids under Ambient Conditions. Chin. J. Chem. 2020, 38, 372-382.

(10) (a) Hoffmann-Röder, A.; Krause, N. Gold(III) Chloride Catalyzed Cyclization of a-Hydroxyallenes to 2,5-Dihydrofurans. Org. Lett. 2001, 3, 2537-2538. (b) Zhou, C.-Y.; Chan, P. W. H.; Che, C.-M. Gold(III) Porphyrin-Catalyzed Cycloisomerization of Allenones. Org. Lett. 2006, 8, 325-328. (c) Zhang, Z.; Widenhoefer, R. A. Gold(I)Catalyzed Intramolecular Enantioselective Hydroalkoxylation of Allenes. Angew. Chem., Int. Ed. 2006, 46, 283-285. (d) Dudnik, A. S.; Sromek, A. W.; Rubina, M.; Kim, J. T.; Kel'i, A. V.; Gevorgyan, V. Metal-Catalyzed 1,2-Shift of Diverse Migrating Groups in Allenyl Systems as a New Paradigm toward Densely Functionalized Heterocycles. J. Am. Chem. Soc. 2008, 130, 1440-1452. (e) Poonoth, M.; Krause, N. Stereoselective Synthesis of Conjugated Bisallenols as Precursors of Novel Bis(2,5-Dihydrofuran) Derivatives. Adv. Synth. Catal. 2009, 351, 117-122. (f) Lalonde, R. L.; Wang, Z. J.; Mba, M.; Lackner, A. D.; Toste, D. F. Gold(I)-Catalyzed Enantioselective Synthesis of Pyrazolidines, Isoxazolidines, and Tetrahydrooxazines. Angew. Chem., Int. Ed. 2010, 49, 598-601. (g) Okada, T.; Sakaguchi, K.; Shinada, T.; Ohfune, Y. Au-Catalyzed Cyclization of Allenylsilanes. Regioselective Conversion to 2-Amino-4-Silylmethylene $\gamma$-Butyrolactone. Tetrahedron Lett. 2011, 52, 5740-5743. (h) Miles, D. H.; Veguillas, M.; Toste, F. D. Gold(I)-Catalyzed Enantioselective Bromocyclization Reactions of Allenes. Chem. Sci. 2013, 4, 34273431. (i) Muñoz, M. P. Silver and Platinum-Catalysed Addition of O-H and N-H Bonds to Allenes. Chem. Soc. Rev. 2014, 43, 3164-3183. (j) Hu, F.; Xia, Y.; Ma, C.; Zhang, Y.; Wang, J. Cu(I)-Catalyzed Synthesis of Furan-Substituted Allenes by Use of Conjugated Ene-yne Ketones as Carbene Precursors. J. Org. Chem. 2016, 81, 3275-3285. (k) Bogachenkov, A. S.; Dogadina, A. V.; Boyarskaya, I. A.; Boyarskiy, V. P.; Vasilyev, A. V. Synthesis of 1,4-Dihydrophosphinoline 1-Oxides by Acid-Promoted Cyclization of 1-(Diphenylphosphoryl)Allenes. Org. Biomol. Chem. 2016, 14, 1370-1381. (1) Zhou, J.; Fu, C.; Ma, S. GoldCatalyzed Stereoselective Cycloisomerization of Allenoic Acids for Two Types of Common Natural $\gamma$-Butyrolactones. Nat. Commun. 2018, 9, No. 1654. (m) Zorba, L.; Kidonakis, M.; Saridakis, I.; Stratakis, M. Cycloisomerization of Conjugated Allenones into Furans under Mild Conditions Catalyzed by Ligandless Au Nanoparticles. Org. Lett. 2019, 21, 5552-5555. (n) Bernhard, Y.; Gilbert, J.; Bousquet, T.; Favrelle-Huret, A.; Zinck, P.; Pellegrini, S.; Pelinski, L. One-Pot Synthesis of 2,5-Disubstituted Furans through In Situ Formation of Allenes and Enolization Cascade. Eur. J. Org. Chem. 2019, 7870-7873.

(11) (a) Yu, S.; Ma, S. How Easy Are the Syntheses of Allenes? Chem. Commun. 2011, 47, 5384-5418. (b) Neff, R. K.; Frantz, D. E. Recent Advances in the Catalytic Syntheses of Allenes: A Critical Assessment. ACS Catal. 2014, 4, 519-528. (c) Chu, W.-D.; Zhang, Y.; Wang, J. Recent Advances in Catalytic Asymmetric Synthesis of Allenes. Catal. Sci. Technol. 2017, 7, 4570-4579. (d) Armstrong, R. J. Synthesis of Allenes by 1,2-Elimination. Curr. Org. Chem. 2019, 23, 3027-3039. (e) Fu, L.; Greßies, S.; Chen, P.; Liu, G. Recent Advances and Perspectives in Transition Metal-Catalyzed 1,4-Functionalizations of Unactivated 1,3-Enynes for the Synthesis of Allenes. Chin. J. Chem. 2020, 38, 91-100. (f) Shruthi, K. S.; Singh, P.; Prasad, K. R. Stereoselective Synthesis of Functionalized Allenes from Tartaric Acid. Tetrahedron 2020, 76, No. 131706.

(12) (a) Yokota, M.; Fuchibe, K.; Ueda, M.; Mayumi, Y.; Ichikawa, J. Facile Synthesis of 1,1-Difluoroallenes via the Difluorovinylidenation of 
Aldehydes and Ketones. Org. Lett. 2009, 11, 3994-3997. (b) Mori, N.; Obuchi, K.; Katae, T.; Sakurada, J.; Satoh, T. Alkenylation of Thiophenes and Furans at the 2-Position and a Synthesis of Allenes Conjugated with $\alpha, \beta$-Unsaturated Ester with Magnesium Alkylidene Carbenoids. Tetrahedron 2009, 65, 3509-3517. (c) Satoh, T.; Kaneta, H.; Matsushima, A.; Yajima, M. A New Synthesis of $\beta, \gamma$-Unsaturated Esters and Allenic Esters with Construction of a Carbon-Carbon Bond between $\alpha$ - and $\beta$-Positions by the Reaction of Magnesium Alkylidene Carbenoids with Lithium Ester Enolates. Tetrahedron Lett. 2009, 50, 6280-6285. (d) Zhang, Y.; Hao, H.-D.; Wu, Y. An 1,2-Elimination Approach to the Enantioselective Synthesis of 1,3-Disubstituted Linear Allenes. Synlett 2010, 905-908.

(13) (a) Yu, X.; Ren, H.; Xiao, Y.; Zhang, J. Efficient Assembly of Allenes, 1,3-Dienes, and 4H-Pyrans by Catalytic Regioselective Nucleophilic Addition to Electron-Deficient 1,3-Conjugated Enynes. Chem. - Eur. J. 2008, 14, 8481-8485. (b) Todo, H.; Terao, J.; Watanabe, H.; Kuniyasu, H.; Kambe, N. Cu-Catalyzed Regioselective Carbomagnesiation of Dienes and Enynes with Sec- and Tert-Alkyl Grignard Reagents. Chem. Commun. 2008, 1332-1334. (c) Ma, Z.; Zeng, R.; Yu, Y.; Ma, S. Highly Stereoselective Synthesis of 6Perfluoroalkyl-6-Fluoroalka-2,3,5-(Z)-Trienols through Carbometallation-Elimination of 5-Perfluoroalkyl-substituted 4(E)-Alken-2-Ynols with Grignard Reagents. Tetrahedron Lett. 2009, 50, 6472-6475. (d) Zhang, W.; Zheng, S.; Liu, N.; Werness, J. B.; Guzei, I. A.; Tang, W. Enantioselective Bromolactonization of Conjugated (Z)-Enynes. J. Am. Chem. Soc. 2010, 132, 3664-3665. (e) Nishimura, T.; Makino, H.; Nagaosa, M.; Hayashi, T. Rhodium-Catalyzed Enantioselective 1,6Addition of Arylboronic Acids to Enynamides: Asymmetric Synthesis of Axially Chiral Allenylsilanes. J. Am. Chem. Soc. 2010, 132, 1286512867. (f) Xiao, Y.; Zhang, J. Tetrasubstituted Allenes by Pd0Catalyzed Three-Component Tandem Michael Addition/CrossCoupling Reaction. Chem. Commun. 2010, 46, 752-754. (g) Mömming Cornelia, M.; Kehr, G.; Wibbeling, B.; Fröhlich, R.; Schirmer, B.; Grimme, S.; Erker, G. Formation of Cyclic Allenes and Cumulenes by Cooperative Addition of Frustrated Lewis Pairs to Conjugated Enynes and Diynes. Angew. Chem., Int. Ed. 2010, 49, 2414-2417. (h) Yao, Q.; Liao, Y.; Lin, L.; Lin, X.; Ji, J.; Liu, X.; Feng, X. Efficient Synthesis of Chiral Trisubstituted 1,2-Allenyl Ketones by Catalytic Asymmetric Conjugate Addition of Malonic Esters to Enynes. Angew. Chem., Int. Ed. 2016, 55, 1859-1863.

(14) (a) Sanz, R.; Gohain, M.; Miguel, D.; Martínez, A.; Rodríguez, F. Synthesis of 3-Allenylindoles and 3-Dienylindoles by Brønsted Acid Catalyzed Allenylation of 2-Arylindoles with Tertiary Propargylic Alcohols. Synlett 2009, 1985-1989. (b) Fandrick, D. R.; Reeves, J. T.; Tan, Z.; Lee, H.; Song, J. J.; Yee, N. K.; Senanayake, C. H. Regioselective Allene Synthesis and Propargylations with Propargyl Diethanolamine Boronates. Org. Lett. 2009, 11, 5458-5461. (c) Jiang, H.; Wang, W.; Yin, B.; Liu, W. Facile Synthesis of Trisubstituted Allenynes by Phosphane-Mediated Deoxygenation of 2,4-Pentadiyn-1ol. Eur. J. Org. Chem. 2010, 4450-4453.

(15) (a) Shono, T.; Ito, K.; Tsubouchi, A.; Takeda, T. Titanocene(II)Promoted Carbonyl Allenation Utilizing 1,1-Dichloroalk-1-enes. Org. Biomol. Chem. 2005, 16, 2914-2916. (b) Zhou, H.; Liu, G.; Zeng, C. Bismetalated Carbon for Tandem Wittig-Type Reaction via Allylgallation of Magnesium Acetylides: A Convenient and Efficient Method to Allyl Allenes. J. Organomet. Chem. 2008, 693, 787-791. (c) Mundal, D. A.; Lutz, K. E.; Thomson, R. J. A Direct Synthesis of Allenes by a Traceless Petasis Reaction. J. Am. Chem. Soc. 2012, 134, 5782-5785.

(16) (a) Poh, J.-S.; Tran, D. N.; Battilocchio, C.; Hawkins, J. M.; Ley, S. V. A Versatile Room-Temperature Route to Di- and Trisubstituted Allenes Using Flow-Generated Diazo Compounds. Angew. Chem., Int. Ed. 2015, 54, 7920-7923. (b) Wu, C.; Hu, F.; Liu, Z.; Deng, G.; Ye, F.; Zhang, Y.; Wang, J. Cu(I)-Catalyzed Coupling of Diaryldiazomethanes with Terminal Alkynes: An Efficient Synthesis of Tri-Aryl-Substituted Allenes. Tetrahedron 2015, 71, 9196-9201. (c) Ye, F.; Wang, C.; Ma, X.; Hossain, M. L.; Xia, Y.; Zhang, Y.; Wang, J. Synthesis of Terminal Allenes through Copper-Mediated Cross-Coupling of Ethyne with NTosylhydrazones or $\alpha$-Diazoesters. J. Org. Chem. 2015, 80, 647-652. (d) Chu, W.-D.; Zhang, L.; Zhang, Z.; Zhou, Q.; Mo, F.; Zhang, Y.;
Wang, J. Enantioselective Synthesis of Trisubstituted Allenes via $\mathrm{Cu}(\mathrm{I})$ Catalyzed Coupling of Diazoalkanes with Terminal Alkynes. J. Am. Chem. Soc. 2016, 138, 14558-14561. (e) Poh, J.-S.; Makai, S.; von Keutz, T.; Tran, D. N.; Battilocchio, C.; Pasau, P.; Ley, S. V. Rapid Asymmetric Synthesis of Disubstituted Allenes by Coupling of FlowGenerated Diazo Compounds and Propargylated Amines. Angew. Chem., Int. Ed. 2017, 56, 1864-1868. (f) Hossain, M. L.; Wang, J. $\mathrm{Cu}(\mathrm{I})$-Catalyzed Cross-Coupling of Diazo Compounds with Terminal Alkynes: An Efficient Access to Allenes. Chem. Rec. 2018, 18, 15481559.

(17) (a) Lavallo, V.; Frey, G. D.; Kousar, S.; Donnadieu, B.; Bertrand, G. Allene Formation by Gold Catalyzed Cross-Coupling of Masked Carbenes and Vinylidenes. Proc. Natl. Acad. Sci. U.S.A. 2007, 104, 13569-13573. (b) Chen, B.; Wang, N.; Fan, W.; Ma, S. Efficient Synthesis of N-(Buta-2,3-Dienyl) Amides from Terminal N-Propargyl Amides and Their Synthetic Potential towards Oxazoline Derivatives. Org. Biomol. Chem. 2012, 10, 8465-8470. (c) Li, H.; Grassi, D.; Guénée, L.; Bürgi, T.; Alexakis, A. Copper-Catalyzed Propargylic Substitution of Dichloro Substrates: Enantioselective Synthesis of Trisubstituted Allenes and Formation of Propargylic Quaternary Stereogenic Centers. Chem. - Eur. J. 2014, 20, 16694-16706. (d) Yang, Z.; Hao, W.-J.; Wang, S.-L.; Zhang, J.-P.; Jiang, B.; Li, G.; $\mathrm{Tu}$, S.-J. Synthesis of Allenyl Sulfones via a TBHP/TBAI-Mediated Reaction of Propargyl Alcohols with Sulfonyl Hydrazides. J. Org. Chem. 2015, 80, 9224-9230. (e) Luo, H.; Yu, Y.; Ma, S. Suzuki Coupling for Preparation of Allenes - Ligand Effects and Chirality Transfer. Org. Chem. Front. 2016, 3, 1705-1710. (f) Kessler, S. N.; Bäckvall, J.-E. IronCatalyzed Cross-Coupling of Propargyl Carboxylates and Grignard Reagents: Synthesis of Substituted Allenes. Angew. Chem., Int. Ed. 2016, 55, 3734-3738. (g) Ruchti, J.; Carreira, E. M. Rh-Catalyzed Stereospecific Synthesis of Allenes from Propargylic Benzoates and Arylboronic Acids. Org. Lett. 2016, 18, 2174-2176. (h) Ma, S.; Liu, Q.; Tang, X.; Cai, Y. Copper-Catalyzed Synthesis of Tetrasubstituted Allenes from Quaternary Ammonium Salts and Grignard Reagents. Asian J. Org. Chem. 2017, 6, 1209-1212. (i) Zhang, Z.; Shao, X.; Zhang, G.; Li, Q.; Li, X. Highly Efficient Synthesis of Multi-Substituted Allenes from Propargyl Acetates and Organoaluminum Reagents Mediated by Palladium. Synthesis 2017, 49, 3643-3653. (j) Zhang, W.; Huang, C.; Yuan, Y.; Ma, S. Catalytic Transient Leaving Group for AtomEconomic Synthesis of Allenes from 2-Alkynols. Chem. Commun. 2017, 53, 12430-12433. (k) Yang, Y.; Liu, Z.; Porta, A.; Zanoni, G.; Bi, X. Alkynyl N-Nosylhydrazones: Easy Decomposition to Alknynl Diazomethanes and Application in Allene Synthesis. Chem. - Eur. J. 2017, 23, 9009-9013. (1) Domingo-Legarda, P.; Soler-Yanes, R.; Quirós-López, M. T.; Buñuel, E.; Cárdenas, D. J. Iron-Catalyzed Coupling of Propargyl Bromides and Alkyl Grignard Reagents. Eur. J. Org. Chem. 2018, 49004904. (m) Guisán-Ceinos, M.; Martín-Heras, V.; Soler-Yanes, R.; Cárdenas, D. J.; Tortosa, M. Copper-Catalysed Cross-Coupling of Alkyl Grignard Reagents and Propargylic Ammonium Salts: Stereospecific Synthesis of Allenes. Chem. Commun. 2018, 54, 8343-8346. (n) Shao, X. B.; Zhang, Z.; Li, Q. H.; Zhao, Z. G. Synthesis of Multi-Substituted Allenes from Organoalane Reagents and Propargyl Esters by Using a Nickel Catalyst. Org. Biomol. Chem. 2018, 16, 4797-4806. (o) Wang, H.; Luo, H.; Zhang, Z.-M.; Zheng, W.-F.; Yin, Y.; Qian, H.; Zhang, J.; Ma, S. Pd-Catalyzed Enantioselective Syntheses of Trisubstituted Allenes via Coupling of Propargylic Benzoates with Organoboronic Acids. J. Am. Chem. Soc. 2020, 142, 9763-9771. (p) Taj Muhammad, M.; Jiao, Y.; Ye, C.; Chiou, M.-F.; Israr, M.; Zhu, X.; Li, Y.; Wen, Z.; Studer, A.; Bao, H. Synthesis of Difluoromethylated Allenes through Trifunctionalization of 1,3-Enynes. Nat. Commun. 2020, 11, No. 1881.

(18) (a) Crabbé, P.; Fillion, H.; André, D.; Luche, J.-L. Efficient Homologation of Acetylenes to Allenes. J. Chem. Soc. Chem. Commun. 1979, 859-860. (b) Searles, S.; Li, Y.; Nassim, B.; Lopes, M.-T. R.; Tran, P. T.; Crabbé, P. Observation on the Synthesis of Allenes by Homologation of Alk-1-Ynes. J. Chem. Soc., Perkin Trans. 1 1984, 1, $747-751$.

(19) Huang, X.; Ma, S. Allenation of Terminal Alkynes with Aldehydes and Ketones. Acc. Chem. Res. 2019, 52, 1301-1312. 
(20) Ma, S.; Hou, H.; Zhao, S.; Wang, G. Efficient Synthesis of Optically Active 2,3-Allenols via the Simple CuBr-Mediated Reaction of Optically Active Propargylic Alcohols with Paraformaldehyde. Synthesis 2002, 1643-1645.

(21) Nakamura, H.; Sugiishi, T.; Tanaka, Y. Synthesis of Allenes via CuBr-Catalyzed Homologation of Alk-1-Ynes Accelerated by Microwave. Tetrahedron Lett. 2008, 49, 7230-7233.

(22) (a) Kuang, J.; Ma, S. An Efficient Synthesis of Terminal Allenes from Terminal 1-Alkynes. J. Org. Chem. 2009, 74, 1763-1765. (b) Luo, H.; Ma, S. CuI-Catalyzed Synthesis of Functionalized Terminal Allenes from 1-Alkynes. Eur. J. Org. Chem. 2013, 3041-3048.

(23) Kuang, J.; Ma, S. One-Pot Synthesis of 1,3-Disubstituted Allenes from 1-Alkynes, Aldehydes, and Morpholine. J. Am. Chem. Soc. 2010, 132, 1786-1787.

(24) Kitagaki, S.; Komizu, M.; Mukai, C. Can the Crabbé Homologation Be Successfully Applied to the Synthesis of 1,3Disubstituted Allenes? Synlett 2011, 1129-1132.

(25) Kuang, J.; Luo, H.; Ma, S. Copper (I) Iodide-Catalyzed One-Step Preparation of Functionalized Allenes from Terminal Alkynes: Amine Effect. Adv. Synth. Catal. 2012, 354, 933-944.

(26) Jiang, G.-J.; Zheng, Q.-H.; Dou, M.; Zhuo, L.-G.; Meng, W.; Yu, Z.-X. Mild-Condition Synthesis of Allenes from Alkynes and Aldehydes Mediated by Tetrahydroisoquinoline (THIQ). J. Org. Chem. 2013, 78, 11783-11793.

(27) Lustosa, D. M.; Clemens, S.; Rudolph, M.; Hashmi, A. S. K. GoldCatalyzed One-Pot Synthesis of 1,3-Disubstituted Allenes from Benzaldehydes and Terminal Alkynes. Adv. Synth. Catal. 2019, 361, 5050-5056.

(28) Schaarschmidt, M.; Wanner, K. T. Synthesis of Allene Substituted Nipecotic Acids by Allenylation of Terminal Alkynes. J. Org. Chem. 2017, 82, 8371-8388.

(29) (a) Lo, V. K.-Y.; Wong, M.-K.; Che, C.-M. Gold-Catalyzed Highly Enantioselective Synthesis of Axially Chiral Allenes. Org. Lett. 2008, 10, 517-519. (b) Lo, V. K.-Y.; Zhou, C.-Y.; Wong, M.-K.; Che, C.-M. Silver(I)-Mediated Highly Enantioselective Synthesis of Axially Chiral Allenes under Thermal and Microwave-Assisted Conditions. Chem. Commun. 2010, 46, 213-215.

(30) (a) Ma, S. Some Typical Advances in the Synthetic Applications of Allenes. Chem. Rev. 2005, 105, 2829-2872. (b) Neff, R. K.; Frantz, D. E. Recent Applications of Chiral Allenes in Axial-to-Central Chirality Transfer Reactions. Tetrahedron 2015, 71, 7-18.

(31) (a) Ye, J.; Li, S.; Chen, B.; Fan, W.; Kuang, J.; Liu, J.; Liu, Y.; Miao, B.; Wan, B.; Wang, Y.; Xie, X.; Yu, Q.; Yuan, W.; Ma, S. Catalytic Asymmetric Synthesis of Optically Active Allenes from Terminal Alkynes. Org. Lett. 2012, 14, 1346-1349. (b) Periasamy, M.; Sanjeevakumar, N.; Dalai, M.; Gurubrahamam, R.; Reddy, P. O. Highly Enantioselective Synthesis of Chiral Allenes by Sequential Creation of Stereogenic Center and Chirality Transfer in a Single Pot Operation. Org. Lett. 2012, 14, 2932-2935. (c) Ye, J.; Lü, R.; Fan, W.; Ma, S. Studies on ZnBr2-Mediated Synthesis of Axially Chiral ArylSubstituted Allenes from Terminal Alkynes, Aromatic Aldehydes and (S)- $\alpha, \alpha$-Diphenylprolinol. Tetrahedron 2013, 69, 8959-8963. (d) Lü, R.; Ye, J.; Cao, T.; Chen, B.; Fan, W.; Lin, W.; Liu, J.; Luo, H.; Miao, B.; Ni, S.; Tang, X.; Wang, N.; Wang, Y.; Xie, X.; Yu, Q.; Yuan, W.; Zhang, W.; Zhu, C.; Ma, S. Bimetallic Enantioselective Approach to Axially Chiral Allenes. Org. Lett. 2013, 15, 2254-2257. (e) Gurubrahamam, R.; Periasamy, M. Copper(I) Halide Promoted Diastereoselective Synthesis of Chiral Propargylamines and Chiral Allenes using 2Dialkylaminomethylpyrrolidine, Aldehydes, and 1-Alkynes. J. Org. Chem. 2013, 78, 1463-1470. (f) Ye, J.; Ma, S. Conquering ThreeCarbon Axial Chirality of Allenes. Org. Chem. Front. 2014, 1, 12101224. (g) Tang, X.; Huang, X.; Cao, T.; Han, Y.; Jiang, X.; Lin, W.; Tang, Y.; Zhang, J.; Yu, Q.; Fu, C.; Ma, S. CuBr2-Catalyzed Enantioselective Routes to Highly Functionalized and Naturally Occurring Allenes. Org. Chem. Front. 2015, 2, 688-691. (h) Periasamy, M.; Reddy, P. O.; Sanjeevakumar, N. Convenient Methods for the Synthesis of Highly Functionalized and Naturally Occurring Chiral Allenes. Tetrahedron: Asymmetry 2014, 25, 1634-1646. (i) Periasamy, M.; Reddy, P. O.; Edukondalu, A.; Dalai, M.; Alakonda, L. M.;
Udaykumar, B. Zinc Salt Promoted Diastereoselective Synthesis of Chiral Propargylamines Using Chiral Piperazines and Their Enantioselective Conversion into Chiral Allenes. Eur. J. Org. Chem. 2014, 6067-6076. (j) Zhang, J.; Ye, J.; Ma, S. Harmony of CdI2 with CuBr for the One-Pot Synthesis of Optically Active $\alpha$-Allenols. Org. Biomol. Chem. 2015, 13, 4080-4089. (k) Huang, X.; Cao, T.; Han, Y.; Jiang, X.; Lin, W.; Zhang, J.; Ma, S. General CuBr2-Catalyzed Highly Enantioselective Approach for Optically Active Allenols from Terminal Alkynols. Chem. Commun. 2015, 51, 6956-6959. (1) Periasamy, M.; Edukondalu, A.; Ramesh, E. Synthesis and Desymmetrization of meso2,3-Diphenylpiperazine for Application in Asymmetric Transformations. ChemistrySelect 2017, 2, 3937-3942. (m) Periasamy, M.; Mohan, L.; Satyanarayana, I.; Reddy, P. O. Enantioselective Synthesis of $\beta$ Allenoates via Phosphine-Catalyzed and ZnI2-Promoted Preparation of Oxazolidines and Propargylamines Using Chiral Amines, 1-Alkynes, and Propiolates. J. Org. Chem. 2018, 83, 267-274. (n) Ma, D.; Duan, X.; Fu, C.; Huang, X.; Ma, S. Dimethylprolinol Versus Diphenylprolinol in $\mathrm{CuBr} 2$-Catalyzed Enantioselective Allenylation of Terminal Alkynols. Synthesis 2018, 50, 2533-2545.

(32) Tang, X.; Zhu, C.; Cao, T.; Kuang, J.; Lin, W.; Ni, S.; Zhang, J.; Ma, S. Cadmium Iodide-Mediated Allenylation of Terminal Alkynes with Ketones. Nat. Commun. 2013, 4, No. 2450.

(33) (a) Zhuang, W.; Saaby, S.; Jørgensen, K. A. Direct Organocatalytic Enantioselective Mannich Reactions of Ketimines: An Approach to Optically Active Quaternary $\alpha$-Amino Acid Derivatives. Angew. Chem., Int. Ed. 2004, 43, 4476-4478. (b) Wada, R.; Shibuguchi, T.; Makino, S.; Oisaki, K.; Kanai, M.; Shibasaki, M. Catalytic Enantioselective Allylation of Ketoimines. J. Am. Chem. Soc. 2006, 128, 7687-7691. (c) Zorba, L. P.; Vougioukalakis, G. C. The KetoneAmine-Alkyne (KA2) Coupling Reaction: Transition Metal-Catalyzed Synthesis of Quaternary Propargylamines. Coord. Chem. Rev. 2020, 429, No. 213603.

(34) Pereshivko, O. P.; Peshkov, V. A.; Van Der Eycken, E. V. Unprecedented $\mathrm{Cu}(\mathrm{I})$-Catalyzed Microwave-Assisted Three-Component Coupling of a Ketone, an Alkyne, and a Primary Amine. Org. Lett. 2010, 12, 2638-2641.

(35) (a) Kuang, J.; Tang, X.; Ma, S. Zinc Diiodide-Promoted Synthesis of Trisubstituted Allenes from Propargylic Amines. Org. Chem. Front. 2015, 2, 470-475. (b) Liu, Q.; Tang, X.; Cai, Y.; Ma, S. Catalytic One-Pot Synthesis of Trisubstituted Allenes from Terminal Alkynes and Ketones. Org. Lett. 2017, 19, 5174-5177.

(36) (a) Pinaka, A.; Vougioukalakis, G. C. Using Sustainable Metals to Carry out "Green" Transformations: Fe- and Cu-Catalyzed $\mathrm{CO} 2$ Monetization. Coord. Chem. Rev. 2015, 288, 69-97. (b) Tzouras, N. V.; Stamatopoulos, I. K.; Papastavrou, A. T.; Liori, A. A.; Vougioukalakis, G. C. Sustainable Metal Catalysis in C-H Activation. Coord. Chem. Rev. 2017, 343, 25-138. (c) Liori, A. A.; Stamatopoulos, I. K.; Papastavrou, A. T.; Pinaka, A.; Vougioukalakis, G. C. A Sustainable, User-Friendly Protocol for the Pd-Free Sonogashira Coupling Reaction. Eur. J. Org. Chem. 2018, 6134-6139. (d) Papastavrou, A. T.; Pauze, M.; GomezBengoa, E.; Vougioukalakis, G. C. Unprecedented Multicomponent Organocatalytic Synthesis of Propargylic Esters via CO2 Activcation. Chem CatChem 2019, 11, 5379-5386. (e) Adejumo, T. T.; Tzouras, N. V.; Zorba, L. P.; Radanović, D.; Pevec, A.; Grubišić, S.; Mitić, D.; Anđelković, K. K.; Vougioukalakis, G. C.; Čobeljić, B.; Turel, I. Synthesis, Characterization, Catalytic Activity, and DFT Calculations of $\mathrm{Zn}(\mathrm{II})$ Hydrazone Complexes. Molecules 2020, 25, No. 4043. (f) Neofotistos, S. P.; Tzouras, N. V.; Pauze, M.; Gómez-Bengoa, E.; Vougioukalakis, G. C. Manganese-Catalyzed Multicomponent Synthesis of Tetrasubstituted Propargylamines: System Development and Theoretical Study. Adv. Synth. Catal. 2020, 362, 3872-3885. (g) Tonis, E.; Stein, F.; Stamatopoulos, I. K.; Stubbe, J.; Zarkadoulas, A.; Sarkar, B.; Vougioukalakis, G. C. A Pd-Free Sonogashira Coupling Protocol Employing an In-Situ-Prepared Copper/Chelating 1,2,3-Triazolylidene System. Synlett 2021, 32, 616-620.

(37) Tzouras, N. V.; Neofotistos, S. P.; Vougioukalakis, G. C. ZnCatalyzed Multicomponent KA2 Coupling: One-Pot Assembly of Propargylamines Bearing Tetrasubstituted Carbon Centers. ACS Omega 2019, 4, 10279-10292. 
(38) Pierce, C. J.; Nguyen, M.; Larsen, C. H. Copper/Titanium Catalysis Forms Fully Substituted Carbon Centers from the Direct Coupling of Acyclic Ketones, Amines, and Alkynes. Angew. Chem., Int. Ed. 2012, 51, 12289-12292.

(39) Zhou, J.; Xu, W.; You, Z.; Wang, Z.; Luo, Y.; Gao, L.; Yin, C.; Peng, R.; Lan, L. A New Type of Power Energy for Accelerating Chemical Reactions: The Nature of a Microwave-Driving Force for Accelerating Chemical Reactions. Sci. Rep. 2016, 6, No. 25149.

(40) Periasamy, M.; Reddy, P. O.; Satyanarayana, I.; Mohan, L.; Edukondalu, A. Diastereoselective Synthesis of Tetrasubstituted Propargylamines via Hydroamination and Metalation of 1-Alkynes and Their Enantioselective Conversion to Trisubstituted Chiral Allenes. J. Org. Chem. 2016, 81, 987-999.

(41) (a) Price, J. D.; Johnson, R. P. Cumulene Photochemistry: Photoreactions of a Strained 1.2-Cyclooctadiene. J. Org. Chem. 1991, 56, 6372-6376. (b) Hayashi, R.; Hsung, R.; Feltenberger, J. B.; Lohse, A. G. Regio- and Stereoselective Isomerizations of Allenamides: Synthesis of 2-Amido-Dienes and Their Tandem IsomerizationElectrocyclic Ring-Closure. Org. Lett. 2009, 11, 2125-2128. (c) Kim, J. H.; Kim, S. W.; Jung, S. M.; Ahn, K.-H.; Kang, E. J. Regioselectivities in Fe(III)-catalyzed Cycloisomerization Reactions of $\gamma$-Allenyl Alcohol. Bull. Korean Chem. Soc. 2015, 36, 2846-2850. (d) Titov, A. A.; Kobzev, M. S.; Borisova, T. N.; Listratova, A. V.; Evenko, T. V.; Varlamov, A. V.; Voskressensky, L. G. Facile Methods for the Synthesis of 8-Ylidene1.2.3.8-tetrahydrobenzazecines. Eur. J. Org. Chem. 2020, 3041-3049.

(42) Derosa, J.; Cantu, A. L.; Boulous, M. N.; O’Duill, M. L.; Turnbull, J. L.; Liu, Z.; De La Torre, D. M.; Engle, K. M. Palladium(II)-Catalyzed Directed anti-Hydrochlorination of Unactivated Alkynes with HCl. J. Am. Chem. Soc. 2017, 139, 5183-5193.

(43) Chamduang, C.; Pingaew, R.; Prachayasittikul, V.; Prachayasittikul, S.; Ruchirawat, S.; Prachayasittikul, V. Novel Triazole-Tetrahydroisoquinoline Hybrids as Human Aromatase Inhibitors. Bioorg. Chem. 2019, 93, No. 103327.

(44) Cheng, X.; Jiang, X.; Yu, Y.; Ma, S. Efficient Synthesis of 3Chloromethyl-2 $(5 \mathrm{H})$-furanones and 3-Chloromethyl- 5,6-dihydropyran-2-ones via the $\mathrm{PdCl} 2$-Catalyzed Chlorocyclocarbo-nylation of 2,3or 3,4-Allenols. J. Org. Chem. 2008, 73, 8960-8965.

(45) Pellicciari, R.; Natalini, B.; Sadeghpour, B. M.; Marinozzi, M.; Snyder, J. P.; Williamson, B. L.; Kuethe, J. T.; Padwa, A. The Reaction of $\alpha$-Diazo- $\beta$-Hydroxy Esters with Boron Trifluoride Etherate: Generation and Rearrangement of Destabilized Vinyl Cations. A Detailed Experimental and Theoretical Study. J. Am. Chem. Soc. 1996, $118,1-12$.

(46) Cai, Y.; Tang, X.; Ma, S. Identifying a Highly Active Copper Catalyst for KA2 Reaction of Aromatic Ketones. Chem. - Eur. J. 2016, 22, 2266-2269.

(47) Palchak, Z. L.; Lussier, D. J.; Pierce, C. J.; Larsen, C. H. Synthesis of Tetrasubstituted Propargylamines from Cyclohexanone by SolventFree Copper(II) Catalysis. Green Chem. 2015, 17, 1802-1810.

(48) Abrams, S. R.; Shaw, A. C. On the Mechanism of 1,3-Prototropic Shifts in Acetylene-Allene Isomerizations. J. Org. Chem. 1987, 52, 1835-1839.

(49) Takagi, K.; Fukuda, H.; Shuto, S.; Otaka, A.; Arisawa, M. Safe Removal of the Allyl Protecting Groups of Allyl Esters Using a Recyclable, Low-Leaching and Ligand-Free Palladium Nanoparticle Catalyst. Adv. Synth. Catal. 2015, 357, 2119-2124.

(50) Xu, M.; Ren, T.-T.; Li, C.-Y. Gold-Catalyzed Oxidative Rearrangement of Homopropargylic Ether via Oxonium Ylide. Org. Lett. 2012, 14, 4902-4905.

(51) Okamoto, S.; Sato, H.; Sato, F. Highly Efficient Synthesis of Alka1,3-dien-2-yltitanium Compounds from Alka-2.3-dienylcarbonates. A New, Practical Synthesis of 1.3-dienes and 2-iodo-1.3-dienes. Tetrahedron Lett. 1996, 37, 8865-8868. 